\title{
Patterns in the composition of ground-dwelling spider communities in the Pilbara bioregion, Western Australia
}

\author{
Bradley J. Durrant ${ }^{1}$, Mark S. Harvey ${ }^{2,4}$, Volker W. Framenau ${ }^{2,4}$, Ricardo Ott ${ }^{2,3}$ \\ and Julianne M. Waldock ${ }^{2}$ \\ ${ }^{1}$ Department of Environment and Conservation, PO Box 51, Wanneroo, Western Australia 6946, Australia. \\ Email: bradley.durrant@dec.wa.gov.au \\ ${ }^{2}$ Department of Terrestrial Zoology, Western Australian Museum, Locked Bag 49, Welshpool DC, \\ Western Australia 6986, Australia. \\ ${ }^{3}$ Museu de Ciências Naturais, Fundação Zoobotânica do Rio Grande do Sul, Rua Dr. Salvador França, 1427, 90690-000, \\ Porto Alegre, Rio Grande do Sul, Brazil. \\ ${ }^{4}$ School of Animal Biology, University of Western Australia, Crawley, Western Australia 6009, Australia.
}

\begin{abstract}
Ground-dwelling spiders were sampled at 304 quadrats in 24 survey areas chosen to represent the geographical extent and diversity of terrestrial environments in the Pilbara region of Western Australia, an area of approximately $179,000 \mathrm{~km}^{2}$. Only taxa that were primarily ground-dwelling and were taxonomically robust were identified to species level. A total of 375 species comprising 14 families was recorded. The families Salticidae (93 species), Zodariidae (71 species) and Oonopidae (70 species) showed marked species-level radiation. After excluding quadrats that were burnt or flooded during the sampling period, the distribution data of 375 species from 294 quadrats were analysed, with an average of $12.9(S D=6.8)$ species per quadrat. Singletons (species recorded at only one quadrat) constituted $26 \%$ (98 species) of the total number of species, and were found more frequently in the Roebourne and Fortescue subregions. Species assemblages were indistinct at the quadrat level, but significant clustering occurred when the data were pooled into the 24 survey areas. The arrangement of the survey areas on an MDS ordination plot was analogous with their spatial positions on a map, in particular the division into a northern and southern Pilbara with the Fortescue cluster running in between. This division was also evident with a number of strong allopatric species distributions. The separation of the survey area clusters was correlated with variation in annual precipitation, latitude and dry season precipitation. Given the sporadic nature of rain events in the Pilbara bioregion and the limitations of the climatic data, however, some caution is advised in interpreting these results.
\end{abstract}

\section{INTRODUCTION}

Regional-scale approaches to surveying spiders have been adopted in Western Australia only over the last 20 years, with the Kimberley rainforest survey in the far north (Main 1991), and the Carnarvon Basin (Harvey et al. 2000) and agricultural zone surveys (Durrant 2004; Guthrie and Waldock 2004; Harvey et al. 2004). All three surveys aimed to document the fauna's composition and distribution across the relevant landscapes, but only the last two could be considered spatially representative and seasonally comprehensive, with 63 and 304 quadrats, respectively, and a sampling time frame that covered a 12 month period. Both surveys revealed patterns of endemism as well as correlations between composition and environmental attributes, both climate and soil (Harvey et al. 2000, 2004; Durrant 2004; Guthrie and Waldock 2004). In contrast, other collections of ground-dwelling spiders in north-western Australia have been opportunistic or highly localised. Most have been confined to mining tenements as part of the Western Australian government's environmental impact assessment process.

Industrial development in the Pilbara bioregion of north-western Western Australia commenced when the first pastoral leases were established on the Roebourne Plains in 1863. Within 60 years, this industry had extended over most of the region. The associated depletion of native grasses through grazing and burning has paved the way for perennial buffel grass (Cenchrus ciliaris L.) to 
colonise much of the region, further displacing indigenous shrub and grass communities. Even the region's most rugged landscape components (with low pastoral value) have not escaped the collateral changes in fire regimes (see McKenzie et al. 2009). Mining has also played an ever-increasing role in changing Pilbara landscapes. From a few lead and copper mines opened in the late $19^{\text {th }}$ century, numerous areas are now dedicated to infrastructure associated with gold, iron ore and salt mines.

Several spider families and genera have been revised in Australia in the past 10 years, with a significant proportion of the Western Australian material coming from the Carnarvon Basin survey. These revisions include the Lamponidae (Platnick 2000), Prodidomidae (Platnick and Baehr 2006), Zodariidae (e.g. Baehr 2003a, b, 2004, 2005; Baehr and Churchill 2003), Lycosidae (e.g. Framenau 2005, 2006a, 2007; Yoo and Framenau 2006; Framenau and Baehr 2007; Langlands and Framenau 2010), Ammoxenidae (Platnick 2002), Cithaeronidae (Platnick 2002), Gallieniellidae (Platnick 2002), Trochanteriidae (Platnick 2002) and Pholcidae (Huber 2001). These revisions have allowed us to achieve a much higher level of taxonomic accuracy in determining the Pilbara collection.

This paper documents the composition of the ground-dwelling spider fauna of the Pilbara bioregion and explores their patterns of distribution, particularly in terms of cartographic, climatic and geological attributes.

\section{METHODS}

\section{Study area}

The Pilbara Biological Survey covered about $179,000 \mathrm{~km}^{2}$ of the north-west region of Western Australia. It conforms very closely with the extent of the four IBRA (Interim Biogeographic Regionalisation of Australia) subregions (Thackway and Cresswell 1995) overlying the Pilbara craton. The study area is described in detail in McKenzie et al. (2009). Briefly, the northern half is dominated by the Chichester subregion, which comprises Archaean granite plains and basalt ranges. It is traversed by the De Grey, Oakover, Nullagine, Shaw, Yule and Sherlock river systems, all of which drain to the north. The plains support shrub steppe of Acacia and Triodia hummock grasslands, while the ranges support Eucalyptus tree steppe (Kendrick and McKenzie 2003).

The Hamersley subregion occupies most of the southern Pilbara. It comprises Proterozoic sedimentary ranges and plateaux, dissected by gorges. The Hamersley Range reaches an elevation of $1250 \mathrm{~m}$ above sea level. The fine-textured soils of the valley floors are characterised by Mulga low woodland over bunch grasses while the skeletal soils of the ranges are dominated by Eucalyptus open low woodlands over Triodia hummock grasslands. Drainage is via three river systems: the Fortescue (to the north), Ashburton (to the south) and Robe (to the west) (Kendrick 2003a). The Fortescue Plains subregion separates most of the Chichester from the Hamersley. In the east it comprises alluvial plains of salt marsh, mulga-bunch grass and short grass communities bordering the Fortescue River. Woodlands of river gum and melaleuca occur around large permanent wetlands. The plains narrow in western parts of the subregion, eventually ending where the lower section of the Fortescue River has incised gorges through Chichester landscapes. The Fortescue subregion also marks the northern limit of mulga (Acacia aneura F. Muell.) in Western Australia (Kendrick 2003b). The fourth subregion, the Roebourne Plains, comprises the Pilbara's alluvial and colluvial coastal and subcoastal plains. Grass savannah and dwarf shrub steppes of Acacia dominate the plains, with Triodia hummock grasslands in the higher areas. Marine alluvial flats and river deltas support mangal, samphire and the grass Sporobolus, while eucalypt woodlands fringe the ephemeral drainage lines (Kendrick and Stanley 2003).

Two bioclimatic regions cover the Pilbara. The coast and much of the interior has a semi-desert tropical climate, with summer rainfall and 9-11 months of dry weather, and the remainder a desert climate with summer rain, with up to 12 dry months and higher temperatures. Beard (1990) considered a dry month to be when the amount of precipitation is inadequate to sustain plant growth. The annual average rainfall roughly follows an inland to coastal and southern to northern increase. The annual average of $290 \mathrm{~mm}$ ranges from monthly averages of ca. $2 \mathrm{~mm}$ in September to ca. $66 \mathrm{~mm}$ in February, although year-to-year variation is significant. Cyclonic activity represents a major influence on the rainfall variation. Temperatures range from $11.8^{\circ} \mathrm{C}$ min. and $25.3^{\circ} \mathrm{C}$ max. in July to $25.2^{\circ} \mathrm{C}$ min. and $37.8^{\circ} \mathrm{C}$ max. in January (Beard 1990).

\section{Field sampling strategy}

The survey region was divided into 24 survey areas, comprising 11, 12 or 13 quadrats (Figure 1). The quadrats were chosen to represent the geomorphic (combination of geology and topography) extent of the Pilbara bioregion, with some pseudo-replication to provide better representation of the more extensive landforms within each survey area. Undisturbed or least disturbed examples of these landforms were chosen 


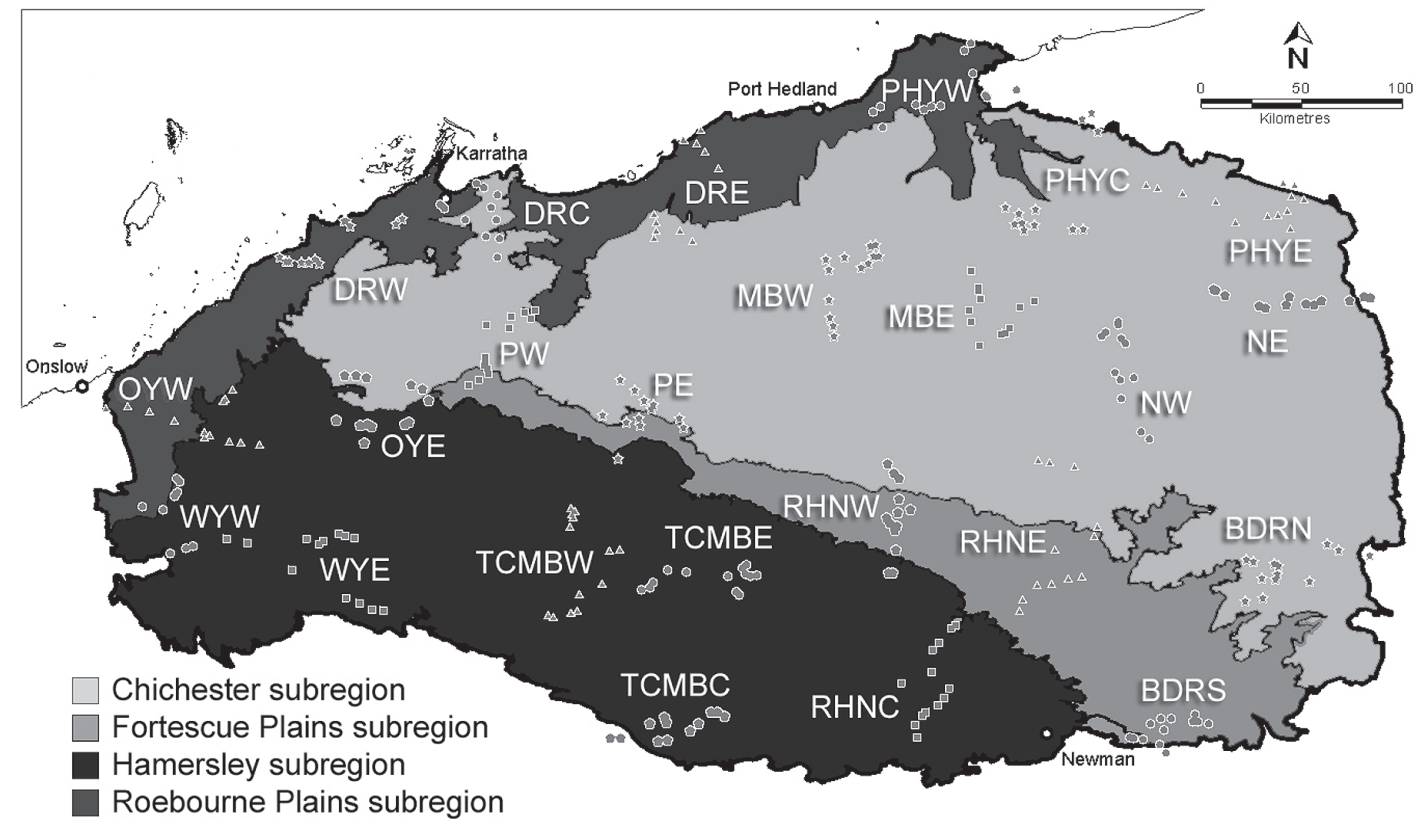

Figure 1 Map of the Pilbara bioregion with the subregions, survey areas and quadrats marked.

to minimise the influence of human-induced factors such as stock grazing. Further details of quadrat selection are provided in McKenzie et al. (2009). Quadrats that were significantly disturbed during the sampling process (predominantly from fire or flood) were removed from the analysis, reducing the number of quadrats from 304 to 294.

Each quadrat was $50 \times 50 \mathrm{~m}$ with a wet pitfall trap at each corner and one in the centre. The pitfall trap consisted of a 2-litre plastic jar with an opening of $85 \mathrm{~mm}$, inserted into a $250 \mathrm{~mm}$ high PVC sleeve (internal diameter of $125 \mathrm{~mm}$ ). Two hoop iron stands inserted between the jar and the sleeve held a $200 \times 200 \mathrm{~mm}$ Colorbond(C) (corrugated steel) roof about 20-30 $\mathrm{mm}$ above the top of the jar. An acrylic ring, with sand glued on, covered the gap between the top of the PVC sleeve and the opening of the jar. One litre of $70 \%$ ethylene glycol was used, with $4 \%$ formaldehyde added as a fixative.

Quadrats in the DRC, DRE, DRW (Dampier/ Roebourne central, east and west), NE, NW (Nullagine east and west), PE, PW (Pyramid east and west), RHNC, RHNE, RHNW (Roy Hill/ Newman central, east and west) and WYE and WYW (Wyloo/Yanrey east and west) survey areas were sampled from July/September 2003 to September/October 2004, with 26 quadrats being sampled through to May 2005 due to disturbance issues during the initial sampling period. The remaining survey areas BDRN, BDRS (Balfour Downs/Robertson north and south), MBE, MBW (Marble Bar east and west), OYE, OYW (Onslow/ Yarraloola east and west), PHYC, PHYE, PHYW (Port Hedland/Yarrie central, east and west), TCMBC, TCMBE and TCMBW (Turee Creek/Mt
Bruce central, east and west) were sampled from July/October 2005 to August/September 2006. All pitfall traps were open for at least 12 months.

The samples were sorted to taxonomic order and then the groups of interest were identified to species-level. In most cases only males were identified. Identification of females, i.e. matching males and females, was often impossible at the species level due to lack of taxonomic resolution. Juveniles lack genitalic characters and, in most cases, species identification is impossible based on morphology alone. Identifications within some families were verified at the Western Australian Museum (WAM) and the University of Western Australia. Specimens were stored in $70 \%$ ethanol and lodged in the WAM.

\section{Physical attributes at quadrats}

Details of the environmental attributes recorded for the quadrats are provided in McKenzie et al. (2009). Briefly, 17 climatic variables were derived for each quadrat using BIOCLIM, including annual, seasonal and range values for temperature and precipitation. Multiple soil samples from the top 10 $\mathrm{cm}$ of the profile were taken at each quadrat, then bulked and analysed to measure attributes such as soil texture (\% silt, clay and sand), total nitrogen, phosphorous and potassium, organic carbon and $\mathrm{pH}$. Sixteen locational, landform and vegetation attributes were also generated including latitude, longitude, elevation, slope, aspect, topographic setting, vegetation cover and rockiness. These included a landform attribute for which quadrats were categorised into 13 landform units based on substrate (rocky, sandy or clayey) and position in 
the landscape, ranging from scree slopes and mesas down to riverine levees and claypans.

\section{Analytical strategy}

Relationships between quadrat species richness and environmental attributes were assessed using the one- way analysis of similarity (ANOSIM) and BEST module in Primer (Clarke and Gorley 2006).

Species $\mathrm{x}$ quadrat, species $\mathrm{x}$ survey area, genus $x$ quadrat and genus $x$ survey area matrices were generated from the survey database, then 'singletons' (species found at only one quadrat throughout the entire survey) were removed on the grounds that they would not contribute statistically to this type of analysis. Analyses were based on presence-absence of species at quadrats (and survey areas).

Cluster analysis in PATN (Belbin 1995) was used to investigate patterns of species composition within the survey region. The Czekanowski measure was used to compare the quadrats according to their composition, so that a modified version of the 'unweighted pair group arithmetic averaging' (UPGMA) (Sneath and Sokal 1973; Belbin 1995) hierarchical clustering strategy with the clustering parameter (Beta) set to - 0.1 could be used to classify the quadrats. Structure in the derived quadrat dendrograms was assessed in terms of the environmental attributes, and displayed as univariate 'box-and-whisker' plots to guide further examination of the cluster groups using modules in Primer and Permanova (Clarke and Gorley 2006). For these steps, the resemblance matrix from PATN was imported into Primer and used to produce a MDS (non-metric Multi-Dimensional Scaling) scatterplot, and the quadrat groups from the PATN classification were assessed using Permanova to run a univariate ANOVA.

By combining the quadrat species lists according to survey area, and averaging the relevant environmental variables (latitude, longitude and climate), compositional patterns were also analysed across the 24 survey areas to investigate patterns at a regional rather than a landscape scale.

\section{TAXONOMIC RESULTS AND DISCUSSION}

The most speciose families were the Salticidae (93 species), the Zodariidae (71 species) and the Oonopidae (70 species). The two most widely occurring species were Euasteron sp. 1 (108 quadrats) and Supunna sp. 1 (105 quadrats). Of the 10 most widely occurring species, three were oonopids, three lamponids and two zodariids.

\section{Mygalomorphae}

Mygalomorph ('trapdoor') spiders belong to one of the focal groups in environmental assessment studies, particularly in recent surveys of shortrange endemic taxa (Harvey 2002). Their high conservation value is indicated by the listing of a number of mygalomorph spiders, e.g. Aganippe castellum Main, 1986, Idiosoma nigrum Main, 1952, Kwonkan eboracum Main, 1983, and Moggridgea tingle Main, 1991, on Schedule 1 ('Fauna that is rare or likely to become extinct' of the Wildlife Conservation [Specially Protected Fauna] Notice 2008 of the Western Australian Government). The Western Australian mygalomorph fauna is vast and, despite long-term and ongoing research by Barbara Y. Main (University of Western Australia) and Robert Raven (Queensland Museum), remains poorly known taxonomically for many families and genera (e.g. Barychelidae: Idiommata; Idiopidae: Aganippe; Nemesiidae: Aname, Chenistonia, Kwonkan).

Recently, the Western Australian Museum has initiated a reference collection of male mygalomorph morphospecies to facilitate an assessment of distribution patterns of these spiders. Mygalomorph morphospecies are consecutively numbered ('MYG001', 'MYG002' etc.) to allow a comparison of taxa between different surveys.

\section{Idiopidae}

Fifteen species in the idiopid genus Aganippe are described from Australia (Platnick 2010) and many new species await description (Faulder 1985; Main 1985). The genus is widespread south of the Tropic of Capricorn, from Western Australia to the western flanks of the Great Dividing Range, and most abundant in woodland and semi-arid regions where they live in burrows with a true trapdoor and often with a collar of twig-lines (Main 1985). Aganippe MYG084 was the most commonly collected member of the genus in the Pilbara (found at eight survey quadrats), followed by Aganippe MYG086 (two survey quadrats) and Aganippe MYG083 (single survey quadrat); the WAM collection also holds specimens of the latter from the Hamersley Range.

The genus Eucyrtops currently includes three named species (Platnick 2010), all from Western Australia, although it is believed to occur also in South Australia and north-western Queensland (Main 1985); many undescribed species are known from collections (B.Y. Main, pers. comm.). Eucyrtops is diverse (7 or 8 species) and abundant in the Carnarvon Basin of Western Australia (Main et al. 2000), but only a single species, Eucyrtops MYG080, was found at a total of four quadrats during the Pilbara survey.

Raven and Wishart (2005) recently reviewed the idiopid genus Arbanitis to include only three species, all from New South Wales and Queensland; at the same time they transferred all Western Australian Arbanitis species to Euoplos 
as anticipated by Main (2000). The genus Euoplos includes 15 species in Australia, five of which are known from Western Australia. Main (2000) restricted Euoplos (sub Arbanitis) to occur mainly south of the Tropic of Capricorn. In the Carnarvon Basin of Western Australia, the genus has since been found in fairly high diversity (6 or 7 species) and abundance (Main et al. 2000). Spiders of the genus Euoplos are generally known from damp, shaded habitats in heavy or loamy soils, although some are known from sandy areas (Main 1985, 2000). Spiders in the genus build thick, plug-like doors on their burrows which fit tightly into the rim of the burrow. The Pilbara survey revealed two species of Euoplos, Euoplos MYG081 and Euoplos MYG082, but both only in two and one survey areas, respectively.

\section{Nemesiidae}

Nemesiidae are represented in Western Australia by several genera, including Aname, Chenistonia, Yilgarnia, Stanwellia, Teyl, Kwonkan and Swolnpes. They usually dig burrows in the soil, and do not cover their burrow entrances with lids (Main 1976; Raven 1981). However, several Western Australian species construct trapdoors (Main 1986).

The genus Aname currently includes 33 named species in Australia (Platnick 2010) and is well represented by four named and numerous unnamed species from many regions in Western Australia (B.Y. Main pers. comm.). Spiders of this genus are believed to be most common in sclerophyll forest but are also known from rainforests and deserts (Raven 1981). Aname is one of the most diverse Australian mygalomorph genera and is regularly recorded in spider biological surveys and, with 12 species, the Pilbara survey revealed nearly as many as the Carnarvon Basin survey (13 species; Main et al. 2000). The most common species, Aname MYG001, was found at 17 survey quadrats throughout the Pilbara and is well represented in the collection of the WAM from the region. However, recent preliminary molecular analyses of fragments of the cytochrome c oxidase subunit 1 (CO1) revealed deep substructuring suggesting that more than one species is present within Aname MYG001 (F. Harvey, J. Wojcieszek, M. Rix, unpublished data). Aname MYG100 and MYG099 were the next most common species, found at nine and eight survey quadrats, respectively. Other Aname species, e.g. Aname MYG102 and MYG104, are known only from single quadrats, confirming narrow distributional ranges reported for the genus (e.g. Raven 1985).

The generic boundaries of Chenistonia are disputed (B.Y. Main, pers. comm.). In our identification we followed the revision of Raven (2000) as the most recently published concept of the genus, in which all species of the previous Aname maculata group were included. Only a single species, Chenistonia MYG090, was found during the Pilbara survey at a single quadrat.

The genus Kwonkan occurs widely in Western Australia and is also known from south-western South Australia (Main 1983). It currently includes six named species (Main 1977, 1983). All of these are currently known only from their type specimens. The Pilbara survey revealed four species of Kwonkan and all are comparatively widespread throughout the region. A fifth species, Kwonkan MYG091, is here only tentatively included in the genus and was found at two quadrats.

The genus Yilgarnia is currently known from two described species in Western Australia (Main 2008), but many more undescribed species are known from collections (B.Y. Main, pers. comm.). Generic boundaries between Yilgarnia and Kwonkan remain uncertain as some species have the morphological characteristics of both genera. This indeterminate group was listed as 'Kwonkan/Yilgarnia' in the WAM/DEC Carnarvon survey, where three species were recovered at a range of quadrats (Main et al. 2000). One representative of this group, 'Kwonkan/ Yilgarnia' MYG092, was also found at 6 quadrats during the Pilbara survey.

\section{Ctenizidae}

Members of the ctenizid genus Conothele are found across much of arid and semi-arid Western Australia where they generally dig burrows that are sealed with a tight-fitting lid that is usually very difficult to locate. At least one species is arboreal, living in burrows constructed on the side of tree boles (Main 1985) and juvenile Conothele are believed to disperse via ballooning (Main 1957, 1976), although it is not known what distances are covered.

All of the Western Australian Conothele are unnamed species. With seven morphospecies, the WAM/DEC Carnarvon survey recorded a high diversity within the genus (Main et al. 2000). In contrast, the DEC Pilbara survey found only a single species at a total of eight quadrats.

\section{Actinopodidae}

Ten species of the mouse spider genus Missulena are currently known from Australia (Platnick 2010), eight of which occur in Western Australia, although the validity of $M$. insignis (Cambridge, 1877) is disputed (Faulder 1995a). In Western Australia, the entrance of the burrow of Missulena is ovoid and equipped with two neighbouring doors (Main 1956). Emergent juveniles of Missulena are believed to disperse via ballooning. Four species of Missulena were recorded from the Pilbara with $M$. rutraspina Faulder, 1995, being the most common. 
This species is also known from Victoria and South Australia (Faulder 1995b; Platnick 2010). Missulena MYG117 was collected at only a single quadrat. Four species of Missulena were also found during the Carnarvon survey (Main et al. 2000), and Missulena MYG037 from the Pilbara appears to be the same as Missulena sp. 1 from the Carnarvon survey.

\section{Barychelidae}

Members of the Barychelidae, the 'Brush-footed Trapdoor Spiders' are cryptic spiders. Their burrow often lacks the firm, thick surface door of the Idiopidae or the extensive web of the Dipluridae (Raven 1994).

Only two species of Aurecocrypta, both restricted to Western Australia, are currently described but some undescribed species are currently known from the collection of the WAM (R.J. Raven, pers. comm.). Aurecocrypta MYG113 was collected at five quadrats during the survey.

Synothele is widespread throughout Western and South Australia and a number of species are currently described from Western Australia (Raven 1994). Four species of Synothele were collected during the Pilbara survey of which one, Synothele MYG114, is comparatively common. It is also known from other collections in the region. The remaining three species are known from single or two quadrats each.

Idiommata includes four Australian species and is known mainly from xeric areas but also from rainforests throughout mainland Australia (Raven 1994). A single, very widespread species, Idiommata MYG111, was collected during the Pilbara survey.

\section{Araneomorphae}

\section{Corinnidae}

Members of the Corinnidae are generally fastrunning ground-dwelling spiders, with 22 named Australian species in eight genera (Raven et al. 2002; Platnick 2010). The present survey found 16 species, all tentatively placed in the genus Supunna. Supunna spp. 1, 2 and 9 were quite widespread across most survey quadrats, whereas others were either somewhat or highly restricted.

\section{Gallieniellidae}

The Gallieniellidae are an austral family found in Australia, Africa, Madagascar and South America; the Australian fauna comprises 22 named species in five genera (Platnick 2002, 2010): Meedo, Neato, Oreo, Peeto, and Questo.

Four gallieniellid species were collected during the survey. Meedo houstoni Main, 1987, was found at many quadrats across the Pilbara bioregion; previously, it was known from the Carnarvon region, Barrow Island and, in the Pilbara, from Mundabullangana Station (Harvey et al. 2000; Platnick 2002). Meedo yarragin Platnick, 2002, was recorded from three quadrats in the south-eastern Pilbara, considerably extending its range from the wheatbelt region of Western Australia (Platnick 2002). Meedo sp. 1 was found at an eastern quadrat within the Pilbara. Oreo capensis Platnick, 2002, was recorded from four quadrats, and was previously known from nearby Cape Range, Kennedy Range and Quobba Station (Platnick 2002).

\section{Lamponidae}

The spider family Lamponidae, which is restricted to the Australasian region, currently comprises 187 named species in 22 genera (Platnick 2000, 2004, 2010).

Eight species of Asadipus were identified in the survey, including four putatively new species, and four previously named species. Asadipus auld Platnick, 2000, occurs in central Western Australia and north-western South Australia (Platnick 2000) and was found at one eastern quadrat during the present survey. Asadipus banjiwarn Platnick, 2000, is relatively common throughout the Carnarvon and Goldfields regions of Western Australia (Platnick 2000), and was recorded from six Pilbara quadrats. Asadipus barlee Platnick, 2000, was originally known only from Barlee Range Nature Reserve (Platnick 2000) and was recorded from four Pilbara quadrats, three in the south-western corner and one in the north. Asadipus yundamindra Platnick, 2000, occurs at two widely separated locations in Western Australia (Platnick 2000), and was recorded from four Pilbara locations in the south-eastern sector.

A single species of Bigenditia was found during the survey; this species was found only in the southern regions.

Five species of Lampona were recognised, including three putative new species and two previously described species. Lampona ampeinna Platnick, 2000, is widespread over much of semiarid and arid Australia (Platnick 2000) and is found in the western and northern survey areas. Lampona quinqueplagiata Simon, 1908, is restricted to Western Australia, occurring throughout the Carnarvon and Murchison regions, northwards into the Pilbara (Platnick 2000). It was recorded from three quadrats in the southern regions of the survey area.

The sole species of Lamponata, L. daviesae Platnick, 2000 , is widespread throughout the drier regions of Australia (Platnick 2000), and was recorded from four quadrats throughout the survey area.

Lamponega forceps Platnick, 2000, was found throughout the survey area, and was previously known from a single male collected at Cape Range (Platnick 2000). 
Lamponina scutata (Strand, 1913) is a common, widespread lamponid found throughout much of the drier regions of mainland Australia (Platnick 2000). It was collected from most quadrats during the present survey. Lamponina sp. 1 was found at four quadrats.

Notsodipus meedo Platnick, 2000, was found at many quadrats within the survey area, and was previously known from a number of sites in the Carnarvon area (Platnick 2000).

\section{Lycosidae}

Wolf spiders belong to one of the largest families of spiders (Platnick 2010). The Australian fauna has received considerable taxonomic attention over the last decade and is now recognised to consist of four subfamilies: Zoicinae (e.g. McKay 1979), Venoniinae (Framenau 2006b; Yoo and Framenau 2006), Artoriinae (e.g. Framenau 2005; Framenau 2007), and Lycosinae (e.g. Framenau and Vink 2001; Framenau and Yoo 2006; Framenau and Baehr 2007). The Lycosinae includes the largest of the Australian wolf spiders, often living in permanent burrows, which has allowed them to colonise the arid centre with enormous success (Framenau and Baehr 2007; Langlands and Framenau 2010). Many genera in this subfamily, with the exception of Venatrix and Tuberculosa, have apparently radiated only after the aridification of the Australian continent (Murphy et al. 2006; Langlands and Framenau 2010).

One species of Artoria was collected. It represents the only member of Artoriinae in the survey, a subfamily that is most diverse in the mesic habitats of temperate parts of Australia, generally along the south-eastern coast including Tasmania and in south-western Western Australia. Artoria currently includes 20 named Australian species (Framenau 2008), but many more undescribed species are known (Framenau, unpublished data).

As with Artoria, most Australian species of the genus Venatrix prefer mesic habitats (Framenau and Vink 2001; Framenau 2006c), but the two species recorded from the Pilbara are frequently found in sand and low vegetation near springs and watercourses in the arid zone (Framenau et al. 2006). Venatrix konei (Berland, 1924) disperses well and is also found in New Zealand and New Caledonia (Framenau et al. 2006).

Hogna is a very large cosmopolitan genus with 11 described species in Australia (Platnick 2010). However, many more undescribed species are in museum collections (Framenau, unpublished data). The Pilbara survey recorded a number of Hogna species, one of which, H. crispipes (L. Koch, 1877), is one of the most commonly collected species of the genus in Australia (Framenau, unpublished data). Similar to $V$. konei, $H$. crispipes prefers moderately wet habitats, grassy and sandy areas near open water, and disperses very well. The species has been found from Christmas Island (Indian Ocean), throughout Australia, New Zealand, and the Pacific to Hawaii (Framenau et al. 2006; Framenau, unpublished data).

The endemic Australian genus Hoggicosa was recently revised and includes 10 species, eight of which are found in Western Australia (Langlands and Framenau 2010). Hoggicosa are large, aridadapted lycosids; females live permanently in burrows that some species cover with a hinged trapdoor or a lid made of pebbles. Hoggicosa bicolor (McKay, 1973), H. castanea (Hogg, 1905) and H. alfi Langlands and Framenau, 2010, have a wide distribution throughout arid mainland Australia whereas H. snelli (McKay, 1975) and H. duracki (McKay, 1975) are restricted to the northern parts of Western Australia (Langlands and Framenau 2010).

Knoelle clara (L. Koch, 1877) represents a monotypic genus that is known only from Australia (Framenau 2006a). The species is common north of ca. $30^{\circ} \mathrm{S}$ latitude, where it appears to prefer sandy, open to partly shaded habitats near freshwater, such as creeks, springs and lakes, but it can also be found in sand dunes near beaches.

The concept of the genus Venator is applied in a broader sense for this study to include many medium-sized, light to dark brown species with distinct folium pattern on the dorsal abdomen and distinct black markings of variable shape on the underside of the abdomen (Framenau, unpublished data). This concept clearly represents more than one genus and a large number of species is known from museum collections, most being widespread throughout arid central and Western Australia (Framenau, unpublished data).

Some species recorded from the Pilbara could not be identified to genus level. Much taxonomic work must be done to solve generic relationships within the highly diverse, arid-adapted lycosine fauna of Australia which is estimated to include in excess of 200 species (Framenau, unpublished data).

\section{Oonopidae}

The named oonopid fauna of Australia is not very extensive, with only a handful of species (Raven et al. 2002; Ott and Harvey 2008a, b; Platnick 2010), but several hundred new species are known from museum collections (Harvey, unpublished data). Representatives of seven genera were collected in the present survey, all of which are small, less than $3 \mathrm{~mm}$ in body length.

Six species of Gamasomorpha, all representing unnamed species, were collected, including three widespread species (G. spp. 1, 2 and 4), two moderately distributed species (G. spp. 3 and 6), and one highly localised species (G. sp. 5). 
Genus A was represented by a single species found at two locations. Eight species of genus B were recorded, all of which were found at only one or two locations. Grymeus was represented by 14 species, of which most were widespread across the Pilbara, although two species (G. spp. 8 and 9) were found at single locations. The new genus Cavisternum was represented by a single species, C. clavatum Baehr, Harvey and Smith, 2010, found at most locations. The genus Myrmopopaea was represented by 19 unnamed species, while Opopaea was represented by 21 unnamed species.

\section{Pholcidae}

The Australian pholcid fauna was revised by Huber (2001), who recognised an indigenous fauna of seven genera and 60 named species. A further 40 unnamed species were also noted, along with nine introduced species. The Pilbara survey recorded six species, including five species of Trichocyclus and a single species of Wugigarra.

Trichocyclus aranda (Huber 2001) has been found sporadically throughout southern Northern Territory and the Pilbara region of Western Australia (Huber 2001). It was found at several quadrats here. Trichocyclus gnalooma Huber, 2001, is known only from the northern Pilbara (Huber 2001). Trichocyclus nigropunctatus Simon, 1908, is widespread in the Gascoyne, Carnarvon and Pilbara regions of Western Australia (Huber 2001), and was found exclusively in the western and southern survey quadrats. Trichocyclus warianga Huber, 2001, was previously known only from Barlee Range and Kennedy Range (Huber 2001), and was found throughout the southern quadrats within the Pilbara survey.

A single species of Wugigarra was found at WYE.

\section{Prodidomidae}

The Australian prodidomid fauna was recently revised by Platnick and Baehr (2006), who recorded 138 species within two subfamilies, Prodidominae and Molycriinae. The highly diverse Molycriinae comprises the majority of the fauna and includes six genera.

Eleven species of Cryptoerithrus were found, comprising two previously named species and nine putative new species. Of the named species, C. harveyi Platnick and Baehr, 2006, was found at one location on the southern edge of the survey area; this species was previously known from the south-western Pilbara region, Gascoyne region and extending as far south as the central wheatbelt (Platnick and Baehr 2006). Cryptoerithrus occultus Rainbow, 1915, was found at several locations and was previously known from a wide range of locations throughout Western Australia and South Australia (Platnick and Baehr 2006).
A single species of Myandra was collected at one quadrat.

Of the four species of Nomindra, two appear to represent new species, and two other named species were also collected, N. leeuwenii Platnick and Baehr, 2006, and N. woodstock Platnick and Baehr, 2006. Nomindra leeuwenii has been recorded throughout Western Australia (Pilbara, Gascoyne, wheatbelt), eastern South Australia, south-western Queensland and north-western New South Wales (Platnick and Baehr 2006). Nomindra woodstock was previously known from Woodstock Station and the southern Kimberley (Platnick and Baehr 2006).

Three species of Prodidomus were collected, including P. woodleigh Platnick and Baehr, 2006, and two putative new species. Prodidomus woodleigh was common throughout much of the study area, and was previously known from the western Pilbara and Shark Bay region (Platnick and Baehr 2006).

Two species of Wesmaldra were collected, including a new species and W. hirsti Platnick and Baehr, 2006. Wesmaldra hirsti was originally recorded from two locations in the western region of the Great Sandy Desert (Platnick and Baehr 2006).

Along with three unnamed species of Wydundra, two other species were collected. Wydundra barrow Platnick and Baehr, 2006, was found at many locations, and was previously recorded from northern Western Australia and western Northern Territory (Platnick and Baehr 2006). Wydundra kennedy Platnick and Baehr, 2006, was found throughout the survey area, and has been previously recorded throughout the Pilbara, as well as near Laverton (Platnick and Baehr 2006).

\section{Salticidae}

Jumping spiders represent the most diverse family of spiders with a world fauna of over 5,000 named species (Platnick 2010). The Australian jumping spider fauna is moderately well known at the generic and species levels (Davies and Żabka 1989), although numerous apparently unnamed genera are known from museum collections (M. Żabka, pers. comm.; Waldock, unpublished data). Of the 93 species recognised from the Pilbara Survey, only 23 were also recorded from the Carnarvon Basin survey.

The genus Clynotis was represented by a single species, C. sp. 2, a member of the C. severus species group (Żabka 1991) and recorded only north of the Fortescue.

'Clynotis' sp. 1 is a member of the 'Clynotis' albobarbatus species group (Davies and Żabka 1989), and was recorded throughout the survey region.

The sole species of Cyrba found during the survey, C. sp. 1, was found at five quadrats, but there are 
several specimens of this species from sites in the Kimberley (Drysdale River Station and Mitchell Plateau; Waldock, unpublished data).

Two species of Cytaea were found, C. sp. 2 and C. sp. 3, at only a few quadrats.

Two species of the ant-mimicking genus Damoetas were recorded from this survey, D. sp. 1 , and $D$. sp. 2 . Both species were recorded as singletons.

Three species of Gangus were found, G. sp. 1, G. sp. 2 and G. sp. 3. The first was recorded as a singleton and the other two were uncommon in the southern half of the Pilbara.

Of the 22 species of Grayenulla recorded from the Pilbara survey, only three are described ( $G$. australensis Żabka, 1992, G. spinimana Żabka and Gray, 1992, and G. waldockae Żabka, 1992) with the two former species also recorded in the Carnarvon Basin. This is a notable increase in the species diversity of this Australian endemic genus (Żabka 1992; Żabka and Gray 2002).

Helpis sp. 1 was found at a single quadrat in the southern portion of the survey area.

Six species of Holoplatys were found, $H$. sp. $1, H$. sp. 2, H. sp. 4, H. sp. 6, H. sp. 7 and H. sp. 8. The distribution and occurrence of each species varied greatly.

Lycidas chlorophthalmus (Simon, 1909) and L. chrysomelas (Simon, 1909) are both widespread in the semi-arid regions of Western Australia, with L. chrysomelas recorded as far south as the Darling Scarp (Waldock 2002). Both L. sp. 1 and L. sp. 2 are widespread species of the semi-arid areas of Western Australia (Waldock, unpublished data). Also found in both the Carnarvon Basin and the Pilbara survey was L. sp. 6.

Four species of Neon were collected, of which only N. sp. 1 was found to be widespread, and the others were relatively limited in distribution.

Four species of Ocrisiona were collected during the survey, including O. yakatunyae Żabka, 1990, and three new species, each of which was found at only a few quadrats.

As in the Carnarvon Basin, several species of Paraplatoides occur in the Pilbara, and it is probable that this genus is widespread in the drier areas of Australia other than eastern Australia and New Caledonia as given in Żabka (1992), Waldock (in press).

With the recognition of the genus Pellenes in Australia by Żabka (2006), and the redescription of $P$. bitaeniata (Keyserling, 1882), it is now seen as a common species found throughout the arid and semi-arid regions of Australia (Żabka 2006).

Simaetha knowlesi Żabka, 1994, was found at two northern quadrats and was also found in the Carnarvon Basin. Simaetha tenuior (Keyserling, 1882) is a widespread, mostly coastal species, found in Queensland, south-western Australia, and then north at Barrow Island and Karratha (Żabka 1994). In both the Pilbara and Carnarvon Basin an undescribed species of Simaethula has been recorded as S. sp. 1 (Harvey et al. 2000).

Zebraplatys fractivittata (Simon, 1909) was collected as a singleton in both the Pilbara and Carnarvon Basin, whilst the Pilbara survey confirms the widespread distribution of Z. keyserlingi Żabka, 1992, in this region (Żabka 1992).

Three species of Zenodorus were found. Zenodorus orbiculatus (Keyserling, 1881) is commonly found in the Pilbara region and is also widespread further north (Waldock, unpublished data). Zenodorus sp. 1 was found in both the Pilbara and in the Carnarvon Basin, whereas Z. sp. 2 was recorded only in the Pilbara survey (Harvey et al. 2000).

Ten species belonging to eight unnamed genera were recorded, all belonging to the Unidentati group.

\section{Zodariidae}

The Zodariidae is a diverse, predominantly tropical and subtropical family of medium-sized spiders, commonly associated with ants (Baehr 2003), and in Australia the family is one of the richest spider groups in semi-arid regions. The family is known from 74 genera and 875 species worldwide (Platnick 2010), with this survey collecting 71 species from 15 known genera and three tentative new genera.

Four species of Australutica were collected, all undescribed species. One species was found at only a single location but the other three exhibited some level of localisation. The first was found extensively in the north but not along the south and south-western boundary. The second was common throughout the south but not found north of the Fortescue basin, and the third was found only on the coastal region, the south-west Pilbara and the Fortescue subregion.

Only one undescribed species of Cavasteron was collected at two quadrats in the south-west Pilbara.

Two species of Chilumena were collected, C. reprobans Jocqué, 1995, and one undescribed species. Chilumena reprobans was previously known only from the type locality in the Kimberley region of Western Australia (Jocqué 1995) and was found at two quadrats in the north-western Pilbara, perhaps representing the southern extent of the species' range. The second species was found only in the south-west of the study area, possibly representing a more temperate species.

Euasteron was represented by three species, E. carnarvon Baehr, 2003, and two undescribed species. Euasteron carnarvon was described recently from just south of the Pilbara region, occurring closely 
with two other described Euasteron species that were not collected in this survey (Baehr 2003b). This species was found in the south of the study area. One of the undescribed species was the most common spider species collected in this study (108 quadrats) and found throughout the region except the far eastern interior. The other species was found at only two quadrats in the south.

Ten species of Habronestes were collected, none previously described. Four species were either singletons or restricted to a couple of neighbouring quadrats. The other species were found commonly throughout much of the survey area.

Leptasteron platyconductor Baehr and Jocqué, 2001, was the only member of this genus collected, predominantly in the southern half. The species was previously known only from the Carnarvon Basin study area (Baehr and Jocqué 2001).

Six species of Masasteron were collected, three described species and three undescribed. Masasteron gracilis Baehr, 2004, was collected in the south-west corner of the study area, known previously only from a couple of coastal quadrats south of the Pilbara (Baehr 2004). Masasteron sampeyae Baehr, 2004, was also restricted to the south of the Fortescue subregion but found commonly throughout the interior of the southern Pilbara, although previous to this survey it was known only on the coast, extending from the Pilbara down to the southern part of the state (Baehr 2004). Masasteron tealei Baehr, 2004, was collected throughout most of the survey area, extending its previous known range from just east of the Pilbara (Baehr 2004). Two of the undescribed species were found in the southern Pilbara in only a small number of quadrats but the third was found extensively north of the Fortescue and appears to form an allopatric distributional relationship with M. sampeyae.

Minasteron minusculum Baehr and Jocqué, 2000, was the only representative of this genus found in the survey but was collected extensively throughout most of the study area. The species is known from the southern interior of Western Australia, extending north to the coastal districts of the Pilbara and the Kimberley (Baehr and Jocqué 2000).

Seven undescribed species of Neostorena were collected, scattered through the study area with indistinct distributional patterns.

One undescribed species of Nostera was collected in the southern part of the study area.

Notasteron carnarvon Baehr, 2005, was collected at two quadrats at opposite ends of the study area, the only representative of this genus in this study. It was previously known from just south of the Pilbara region (Baehr 2005).

One undescribed species of Pentasteron was collected at 15 quadrats, restricted to a small section of the northern Pilbara.

One undescribed species of Pseudasteron was collected at a single quadrat in the south of the study area.

Nine species of Spinasteron were collected, four described and five undescribed. The distribution of S. arenarium Baehr, 2003, in the eastern Pilbara concurred with the previously known range, extending to the interior (Baehr and Churchill 2003). Spinasteron barlee Baehr, 2003, was found predominantly in the southern part of the study area, extending its range from just south of the Pilbara region (Baehr and Churchill 2003). Spinasteron longbottom Baehr, 2003, was previously known only from one site in the Kimberley region (Baehr and Churchill 2003) but was collected at two quadrats in the south-western interior of the study area. Spinasteron woodstock Baehr, 2003, was previously known from only one quadrat in the Pilbara region (Baehr and Churchill 2003) but was found commonly through the interior of the study area. The undescribed species showed varying distributions although none was common or wideranging.

Five undescribed species of Storena were collected, three as singletons and two from only a couple of quadrats.

\section{Analytical results and discussion}

\section{Species richness}

A total of 375 species of ground-dwelling spider was collected from 14 families and 89 genera across 294 quadrats; of these, only 56 species are formally named. Ninety-eight are 'singletons' (species that were caught at only one quadrat). Singleton species were found throughout the survey region but more frequently in the Roebourne and Fortescue subregions, with 29 species from 42 quadrats and 25 species from 37 quadrats, respectively, compared to the Chichester and Hamersley subregions with 23 species from 127 quadrats and 21 from 92 quadrats. Thirty eight $(39 \%)$ of the 98 singleton species occurred within $15-20 \mathrm{~km}$ of the edge of the study area, not including the coastline.

An incidence-based species accumulation curve (Figure 2) was run in EstimateS, using Mao Tau (50 randomisations), to provide an understanding of the adequacy of the sampling regime. The curve shows a definite flattening out to a plateau but still shows an increase in new species occurring. The values show that in the last part of the curve a new species is found every three samples.

Seventy-six quadrats had singleton species, 60 with one, 12 with two, two with three and two with four. At most, singleton species accounted 


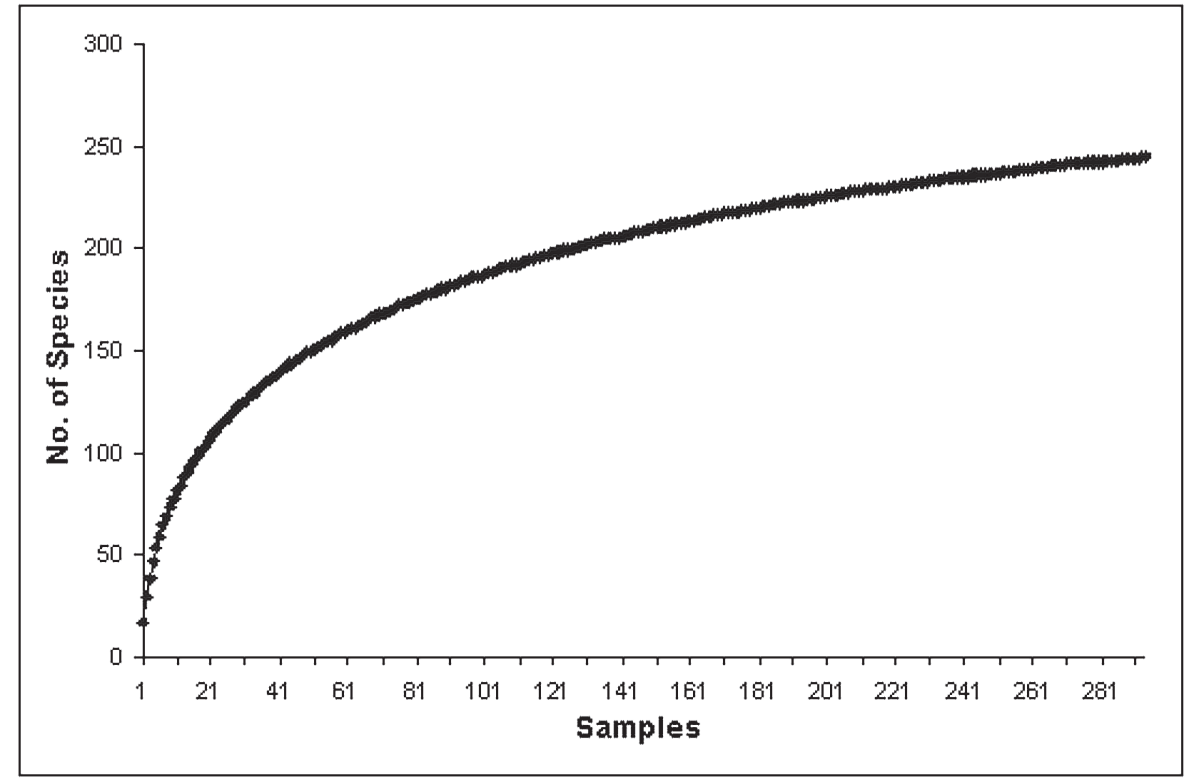

Figure 2 Incidence-based (presence/absence) species accumulation curve of the spider fauna data using the observed number of species (Sobs Mao Tau) in EstimateS version 8.0.0 (Colwell, 2006).

for $29 \%$ of the richness at any one quadrat (NE07) with an average of $9 \%$, not including quadrats with no singleton species. At the survey area (SA) level, all but 3 had singletons (BDRN, DRC and MBW), with the greatest number of singletons at RHNW with 11 species spread across 9 quadrats. The average richness across the 294 quadrats, including singletons, was 13 species per quadrat with a minimum of 1 and a maximum of $43(S D=6.8)$. At the SA level there was an average of 79 species per SA with a minimum of 44 and a maximum of 136 $(S D=24.8)$. The species had an average range of 10 quadrats and 5 survey areas, with a minimum of 1 and a maximum of $108(S D=16.7)$ for the former and a minimum of 1 and a maximum of $23(S D=$ 5.1) for the latter.

There was no significant correlation between quadrat level richness and any habitat or environmental variable.

\section{Quadrat classification}

Quadrats that were disturbed by fire or flood were removed from the analysis, as were singleton species, leaving 294 quadrats and 277 species. The clustering analysis showed no distinct quadrat or species assemblages. Further manipulation of the quadrat level data involved the separation and analysis of common and uncommon species and widespread and localised species. This removed the influence of widespread and common species in driving the assemblages. These analyses also showed indistinct patterns for both quadrats and species.

Classification was also carried out in Primer to determine at what stage the clustering became significant, and what environmental variables were influencing it. Global $\mathrm{R}$ was not significant until the data were split into more than 50 groups of quadrats, and even at this level the Global $R$ was weakly significant.

To test whether spatial autocorrelation was playing a major role in the construction of the

Table 1 Permanova results for PCoQ, Lat and PAnn with significant differences highlighted.

\begin{tabular}{c|c|c|c}
\hline & PCoQ & Lat & PAnn \\
\hline Groups & P(perm) & P(perm) & P(perm) \\
\hline 1,3 & 0.001 & 0.001 & 0.799 \\
1,5 & 0.001 & 0.001 & 0.828 \\
1,2 & 0.797 & 0.001 & 0.631 \\
1,6 & 0.001 & 0.049 & 0.001 \\
1,4 & 0.001 & 0.001 & 0.128 \\
3,5 & 0.001 & 0.233 & 0.71 \\
3,2 & 0.001 & 0.001 & 0.871 \\
3,6 & 0.001 & 0.151 & 0.001 \\
3,4 & 0.001 & 0.001 & 0.163 \\
5,2 & 0.001 & 0.001 & 0.265 \\
5,6 & 0.321 & 0.373 & 0.001 \\
5,4 & 0.001 & 0.001 & 0.217 \\
2,6 & 0.001 & 0.001 & 0.001 \\
2,4 & 0.001 & 0.001 & 0.153 \\
6,4 & 0.001 & 0.001 & 0.011 \\
\hline
\end{tabular}




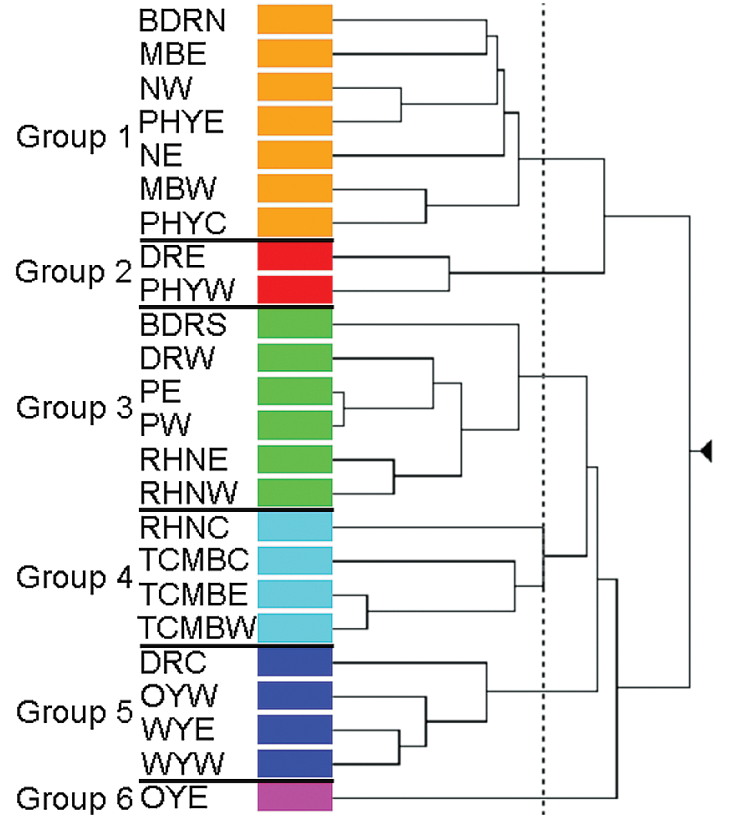

Figure 3 Dendrogram of hierarchical clustering of survey areas. The colours used are consistent with Figures 4 and 5.

quadrat-level classification, the RELATE routine was used to test the similarity between the species composition and the distance between quadrats resemblance matrices. As the two matrices were not significantly related, the distance between quadrats appears to be playing no significant role in determining the observed species composition.

Quadrat composition was also investigated at the genus level, potentially to alleviate any sampling artefacts in the species-level data. Again the results were indistinct and give us some confidence that the species-level taxonomy is not an issue and that the focus should be on the scale of the sampling.

\section{Survey area classification}

The data were lumped into the 24 survey areas and the areas clustered according to their species composition. Only the geographic (latitude, longitude, distance to coast) and climatic variables were used in the survey area analysis, as these were the only variables that could be averaged at this scale.

The cluster analysis yielded six groups as shown in the dendrogram (Figure 3) and the map (Figure 4). The first group consists of all of the Chichester subregion survey areas covering the north-eastern interior, containing PHYE, PHYC, MBW, MBE, NE, NW and BDRN.

The second group is north of group 1 and covers the northern coastal parts of the Roebourne subregion, containing the DRE and PHYW survey areas.

Group 3 covers all of the Fortescue Plain subregion from the south-eastern corner at BDRS through RHNE, RHNW, PE, PW and extending beyond the subregion to the coast at DRW. This continuation of the group to the coast may be an indication that the clustering is significantly influenced by historical factors as well.

Group 4 is south of the Fortescue and covers the eastern part of the Hamersley subregion, containing TCMBW, TCMBE, TCMBC and RHNC.

The fifth group covers the western edges of the study area, the western Hamersley subregion (WYW and WYE), and extends into the western part of the Roebourne subregion (OYW). DRC also falls into this fifth group but lies north-east of OYW, on the other side of DRW.

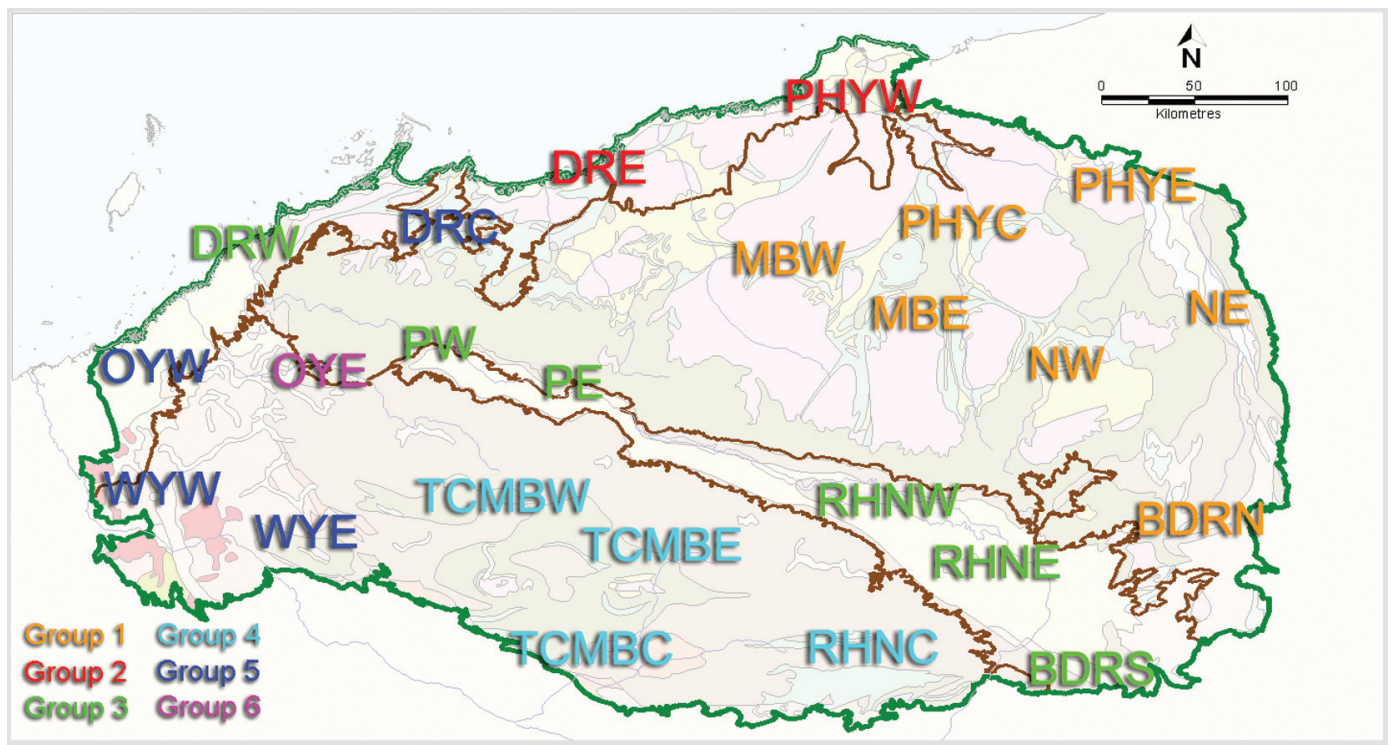

Figure 4 Map of Pilbara bioregion illustrating the survey area clusters. 


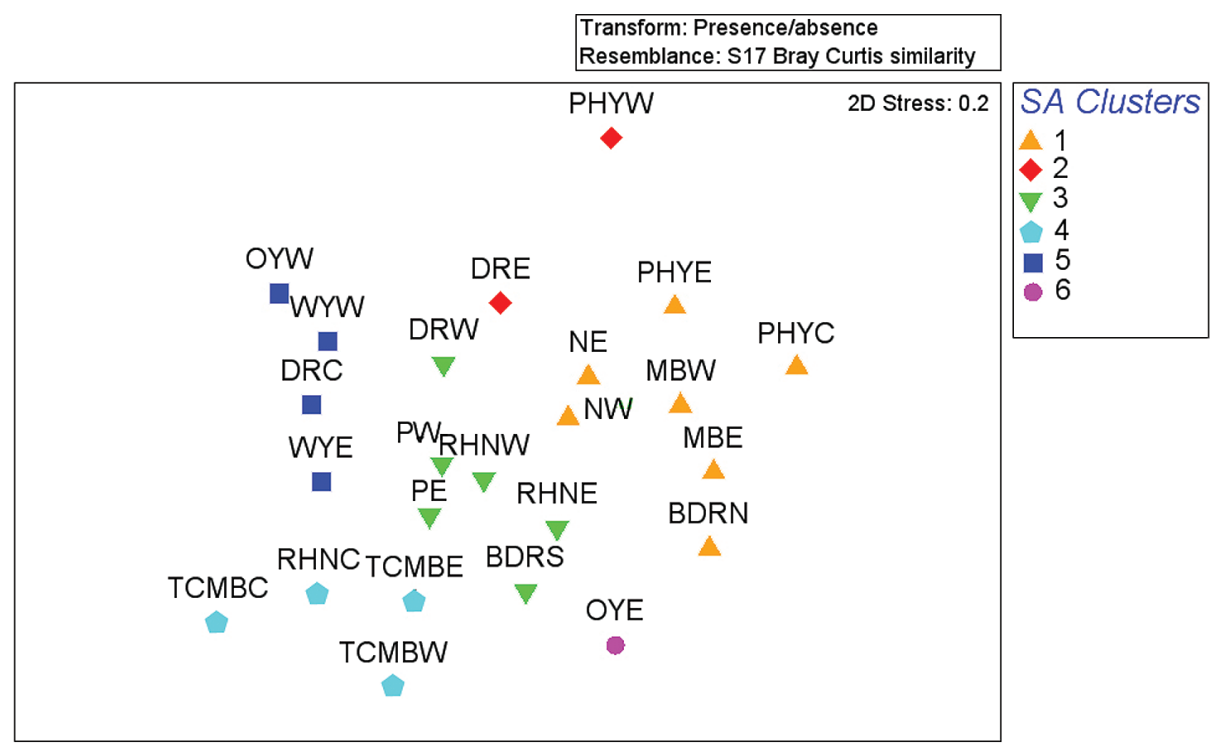

Figure 5 Two-dimensional MDS plot of survey areas, with six group clusters superimposed.

The final group consists of one survey area. OYE lies in the western interior of the study area at a junction between the Hamersley and Chichester subregions. It also partly separates survey areas in the $3^{\text {rd }}$ and $4^{\text {th }}$ groups.

An MDS plot was also constructed to show the spatial relationships between the cluster groups (Figure 5). The placement of the groups is consistent with their spatial arrangement on a map with the Fortescue group, running in between the northern and southern groups, except for OYE which is placed at the opposing end of the Fortescue group.

The PATN-generated box-and-whisker plots (Figure 6) identified a combination of PAnn, PCoQ and Lat as providing the clearest visual separation between the six groups. This was confirmed by running PERMANOVA for each of the variables, using partial sum of squares and unrestricted permutation of the data (9999 permutations). Of the PERMANOVA results for the three variables (Table 1), PCoQ contributed the most to separating the groups, although Lat does separate out many of the same groups. The only two groups that these two were unable to separate were groups 5 and 6 . These two were separated from each other only by PAnn. Given the unreliability of the climatic data, it is difficult to put much faith in this separation between groups 5 and 6 as they are in very similar geographic positions. It is also worth noting that PCoQ is highly correlated with longitude (-0.87).

The two-dimensional MDS, with a relatively high stress of 0.2 , clearly shows the gradients for PCoQ and Lat when plotted as a bubble chart with vectors (Figures 7 and 8). However, the relationship between group 6 (OYE), the other groups and PAnn is not as clear visually with either the twodimensional or three-dimensional MDS.

\section{Vicariant patterns}

Generic distribution patterns were investigated for possible vicariance. There were several examples of clearly restricted distributions, most of them indicating a break in the landscape dividing the Pilbara bioregion along the Fortescue Plain, from the north-west to the south-east. Three examples of individual species are illustrated

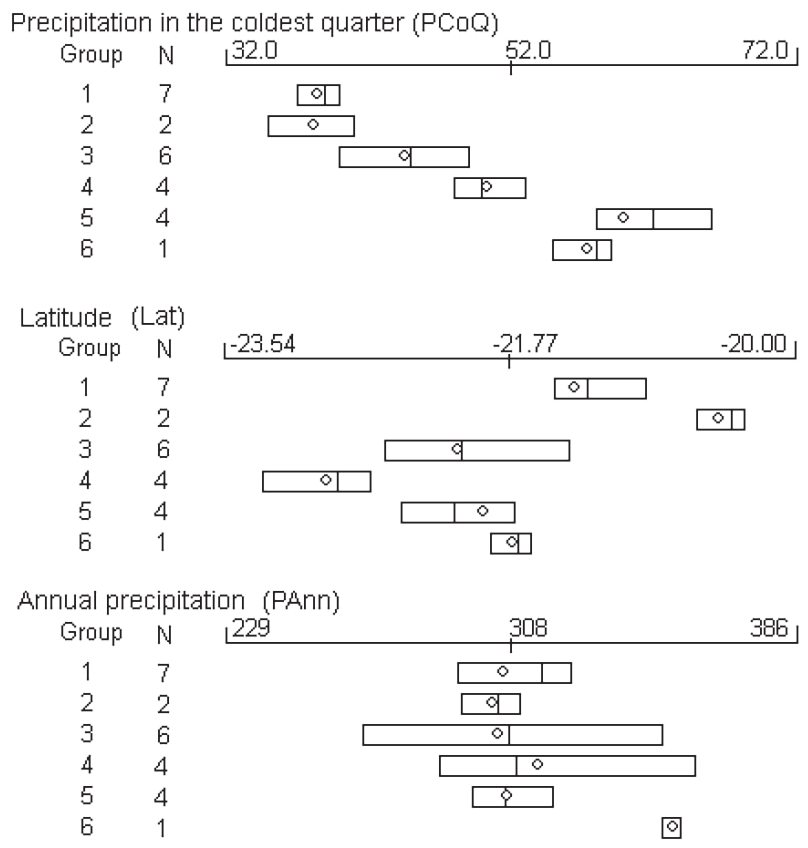

Figure 6 Box-and-whisker plots showing the relationship between each of the six survey area clusters for the three variables, precipitation in the coldest quarter, latitude and annual precipitation. $\mathrm{N}=$ number of survey areas in each group. Standard devation, mean (bar) and median (o) values are indicated. 
in Figure 9, with three very distinct allopatric examples in Figure 10. The three described species provided as examples also occur outside the Pilbara region but their distributions are still consistent with these patterns.

\section{Species composition}

The lack of discrete patterns in species composition at the quadrat-level could indicate a number of issues, not the least being limitations of the sampling protocols. First, it may be that the local habitat-scale variables (landform and soil attributes) that were measured during the survey have little influence on species composition. As such, a lack of meaningful clustering may mean simply that we had not measured the most appropriate variables for the spider groups we were investigating.
Second, the climatic data, as noted earlier, should be treated very guardedly and within a much wider context. At the scale of the individual quadrat, these data, particularly rainfall, should be regarded as unreliable and potentially misleading. Rainfall in the Pilbara can be stochastic at the local scale and it is largely these rainfall events that drive the activity of the local fauna. If there is no rainfall at a quadrat then the chance of effectively sampling the local invertebrate community is potentially greatly diminished. This would result in increased noise in the datasets, through decreased sampling consistency between neighbouring quadrats, and would help explain why pooling the data into their respective survey areas has produced such a contrasting result. It would also possibly explain why the spatial autocorrelation was not significant in a region that has been stable

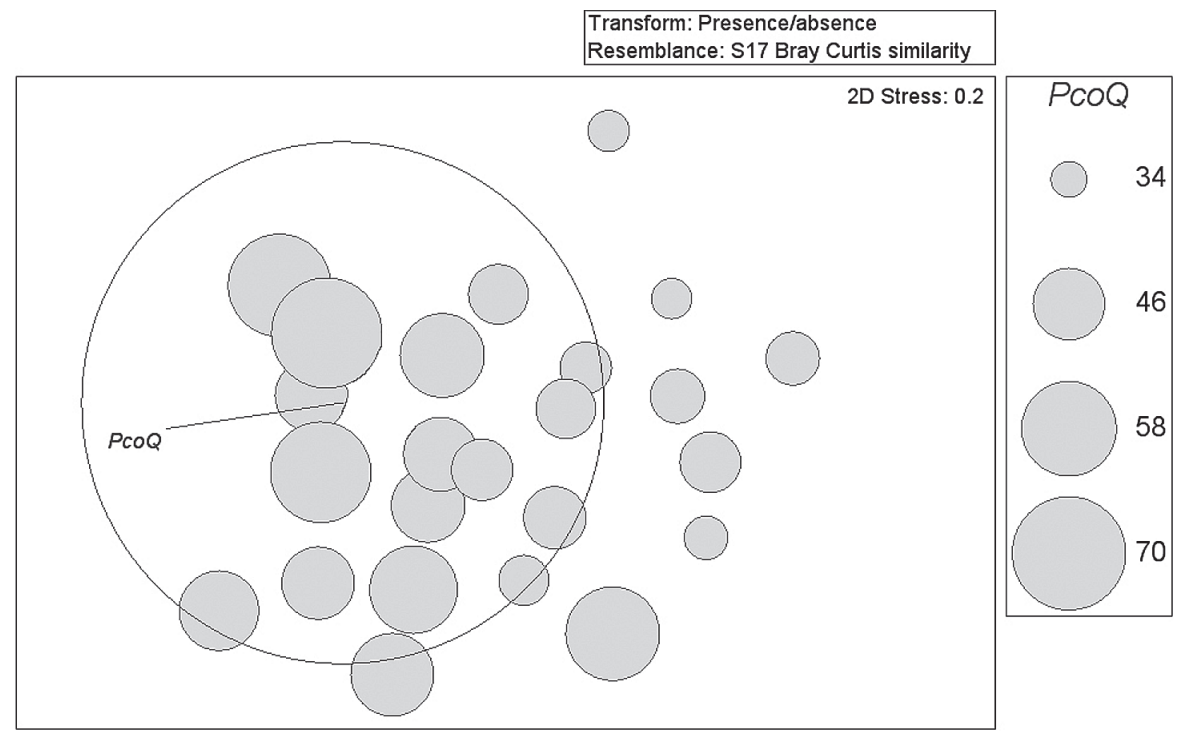

Figure 7 Bubble plot of two-dimensional MDS showing precipitation in the coldest quarter (PCoQ) vector.

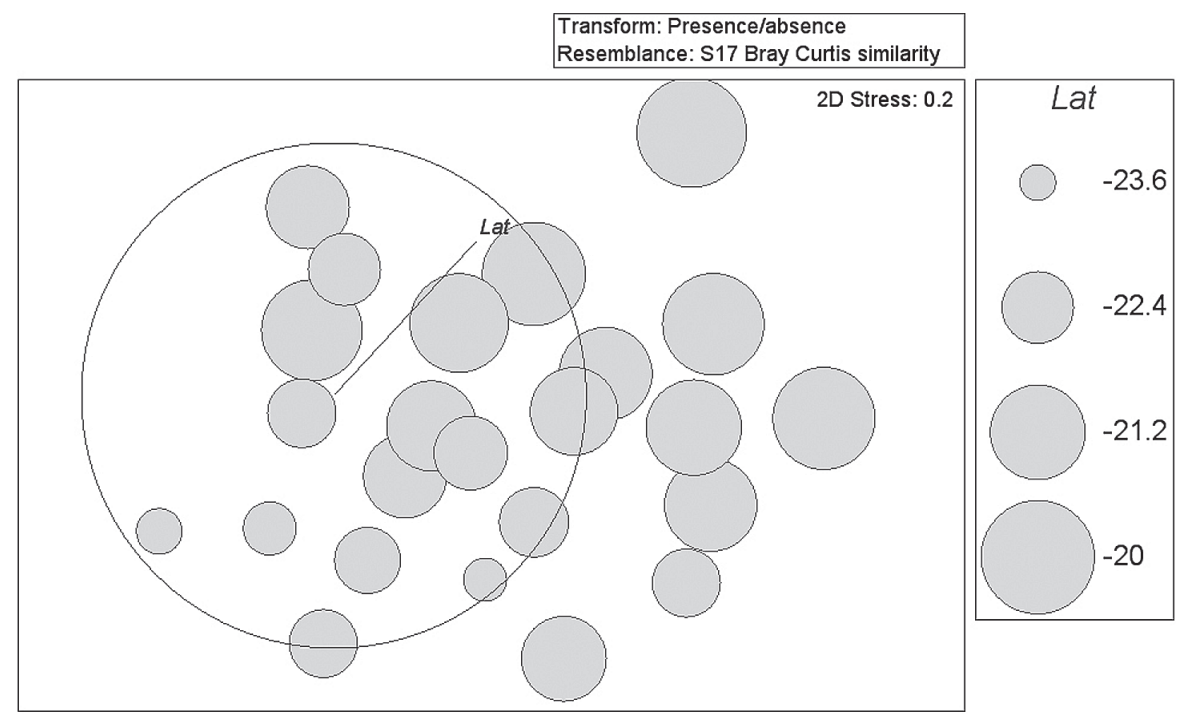

Figure 8 Bubble plot of two-dimensional MDS showing latitude (Lat) vector. 


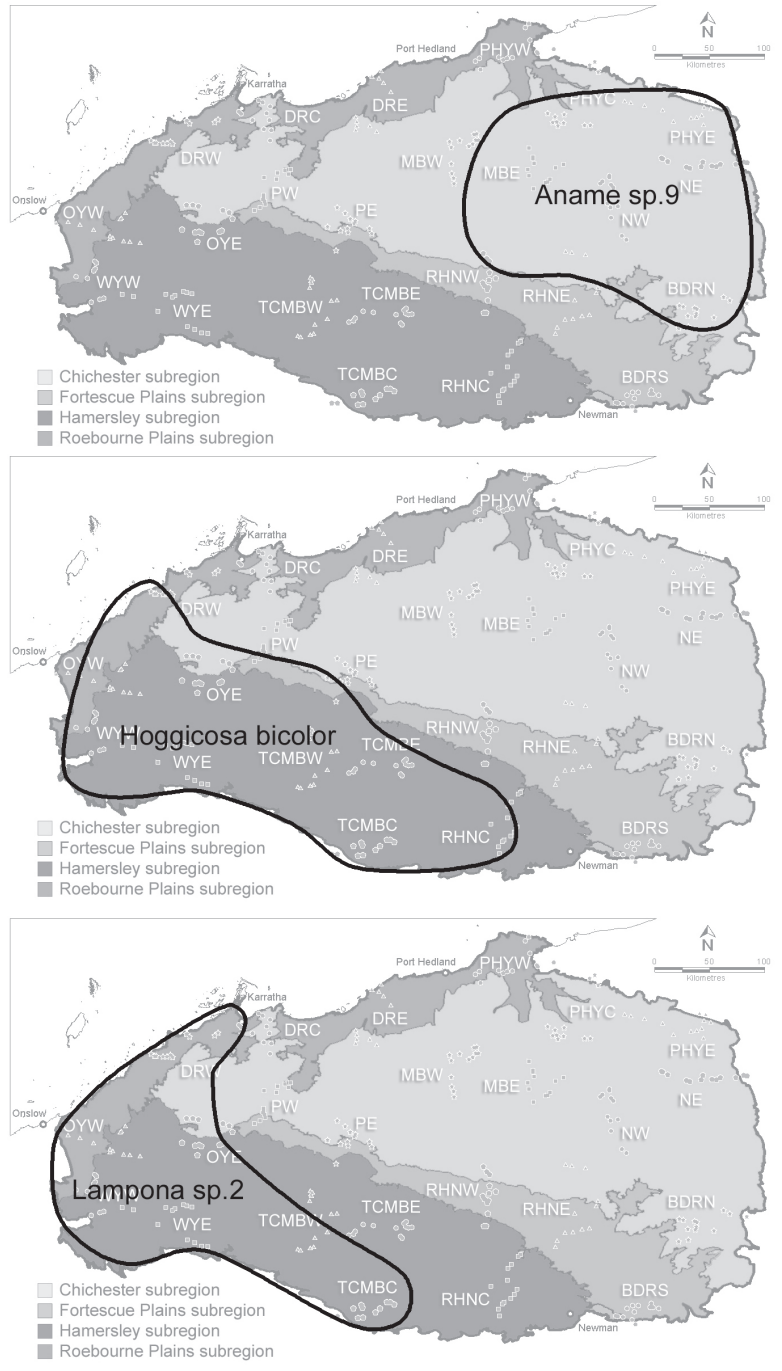

Figure 9 Examples of restricted distributions of commonly collected species.

geologically and climatically for such a long period of time. Unfortunately, local rainfall data were not collected during this survey so there is little way of quantifying this effect, but recent terrestrial invertebrate work in the Pilbara and Midwest regions by consultants surveying trapdoor spiders has shown that a single rainfall event can increase activity and sampling effectiveness by a very significant amount (G. Humphreys, pers. comm.).

In contrast, the results of the survey area analysis provide some insight into the broader compositional patterns in the Pilbara. At this broader scale, the climatic variables can be viewed with more confidence because the amount of noise in the spider sampling data from locally inconsistent rainfall events is reduced. The combination of three environmental variables separated all six survey area clusters.

Precipitation in the coldest quarter (the dry season in the Pilbara) appears to account for much of the separation of the survey area clusters. In the
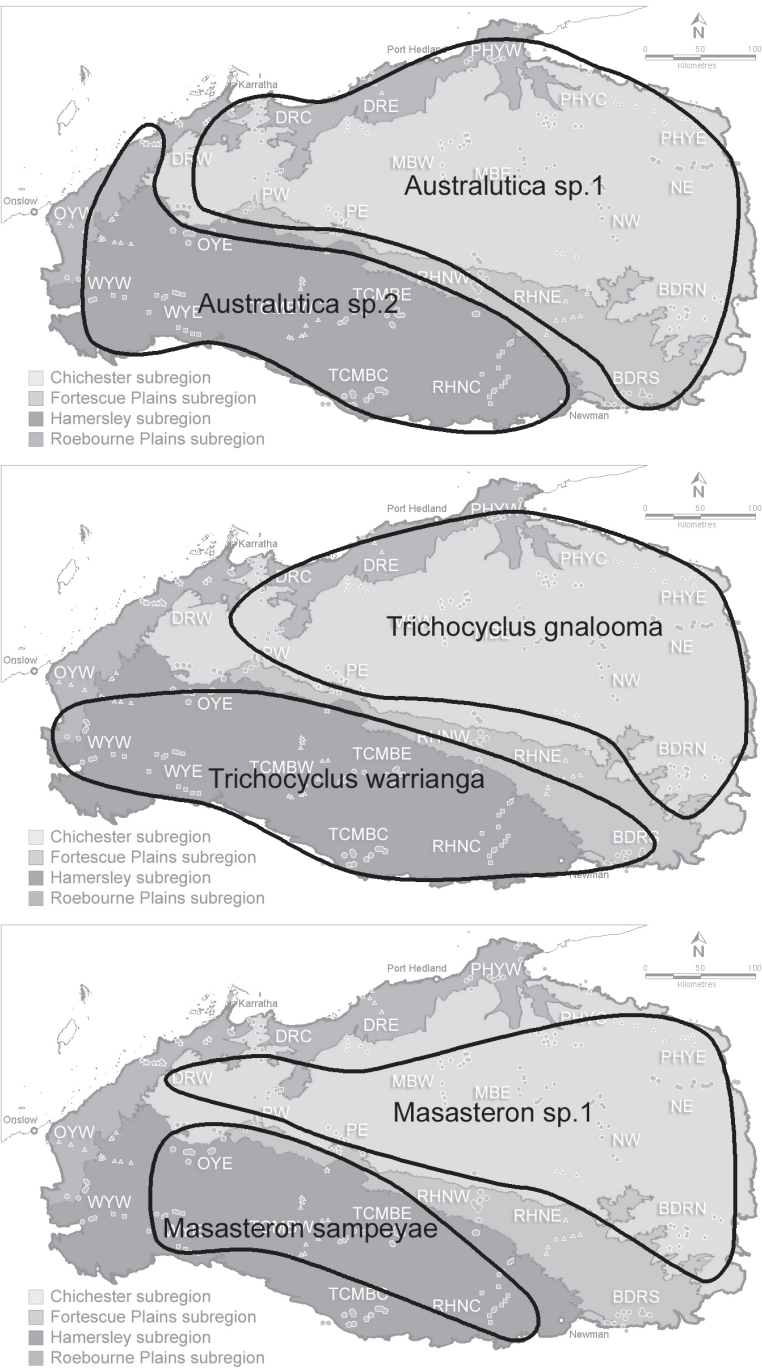

Figure 10 Examples of allopatry illustrating the break between the north and south Pilbara. The distributions shown are based purely on the Pilbara survey material but the known distributions of each species are consistent with the north/south division of the Pilbara.

Pilbara, rainfall in the dry season comes largely from the south, where the more temperate part of the state is having winter rain. Consequently, a gradient of decreasing dry season rainfall runs from the south-west of the Pilbara to the northeast, also highlighting the high correlation with longitude. The increased potential for rain in the dry season in the south-west of the Pilbara opens up the potential in this part of the region for more temperate species to coexist with arid-adapted Pilbara species. So it may be the presence of species adapted to temperate/dry season rainfall that has clustered these southern and south-western survey areas separately from the areas north of the Fortescue.

Latitude has been the focus of many species diversity/richness studies over the years, based on the principle that diversity decreases from a 
tropical to a temperate climate (e.g. Gaston 2000; Hillebrand 2004). Despite some arguments for latitude to be avoided in analysing data from regional-scale surveys (Hawkins and DinizFilho 2004), its inclusion is warranted given the exploratory nature of this study. In this survey the range in latitude is not large, the northernmost part of the region is not tropical, nor the southern temperate, so there is only limited potential for latitude in itself to influence spider composition. The significant correlation with latitude may be related to the influence of the Fortescue River, separating the north Pilbara from the south, and the separation of the Roebourne Plains into northern and southern coastal regions. On the other hand, latitude is highly correlated with several temperature variables, with distance from the coast and possibly with other variables that were not measured.

The third variable used to separate the survey area groups was annual precipitation (PAnn). Unlike PCoQ, PAnn does not show a linear gradient across the Pilbara. Annual rainfall increases from the edges of the study area, including the coast, into the interior and reaching high points over the Hamersley Range, the western part of the Fortescue subregion and the junction of the Fortescue, Hamersley and Chichester subregions. OYE, which on its own constituted group 6, lies in the junction of the Fortescue, Hamersley and Chichester subregions, in an area of high annual rainfall (relative to the rest of the Pilbara). This compares with group 5 (WYE, WYW, OYW and DRW) which all have significantly lower annual rainfall, despite being in the same western section of the Pilbara as OYE. The difference lies in the combination of wet season and dry season rainfall. OYE has a high wet season rainfall compared to OYW, WYE and WYW and a high dry season rainfall compared to DRW. Regardless of the time of year, OYE has one of the highest probabilities of receiving rain.

The survey area clustering conforms to the pattern of the Pilbara's subregions. These subregions differ in geology, soils and vegetation. Harvey et al. (2004) also found that these broad-scale landscape factors were reflected in the survey area clustering for Araneomorphae of the wheatbelt. This, of course, should be kept in perspective as these patterns are based on the 'lumping' of quadrat-based data, resulting in the loss of any fine-scale details, and these broader patterns would likely be driven by a handful of species.

The survey area results also point to the potential influence of historical factors. The Fortescue subregion, which finishes about $100 \mathrm{~km}$ from the coast, comprises the contemporary marshland and alluvial plains of the Fortescue. Beyond the subregion, heading towards the coast following the river, is the ancient floodplain of the Fortescue, now part of the Chichester and Hamersley subregions and continuing into the Roebourne. The inclusion of DRW within the Fortescue group, despite it being on the coast but still along the ancient Fortescue floodplain, indicates an historical element to the patterning. There is, however, no indication of any historical influence in the taxonomic results.

Winter rainfall also showed a correlation with araneomorph composition at a broad scale in the Carnarvon Basin, although some finer-scale variation was associated with claypans and vegetation cover (Harvey et al. 2003). The wheatbelt araneomorph survey revealed potential influence from summer temperature gradients at broad scales, as well as from salinity at the quadrat level (Harvey et al. 2004). The families Salticidae and Zodariidae were considered separately in the wheatbelt study and showed contrasting results. The salticids appeared to be influenced by temperature, rainfall and salinity at the quadrat scale, with distinct assemblages that associated with saltflats. At a broader scale, summer temperatures had some influence, again correlated with latitude (Guthrie and Waldock 2004). The zodariids showed little response to quadrat-level variables but, at a broader scale, summer rainfall appeared to influence assemblages (Durrant 2004). It seems that, at regional scales, both temperature (correlated with latitude) and rainfall have the potential to influence spider assemblages in all three regions.

Techniques for sampling spiders have been studied regularly over the years (e.g. Uetz and Unzicker 1976; Curtis 1980; Churchill and Arthur 1999; Brennan et al. 1999), resulting in a greater capacity for ecological studies to be carried out more efficiently and more comprehensively. The biggest limiting factor for pitfall trapping is its reliance on spider activity. As the activity levels of individual species can vary greatly, spatially and temporally, relying on this method for abundance data should be avoided (Standen 2000). This can make pitfall trapping potentially unsuitable for quantitative studies (Topping and Sutherland 1992) but very good for incidence (presence/absence) and species richness surveys (Uetz and Unzicker 1976; Standen 2000). It is this reliance on activity that has potentially created sampling issues for this survey. The Pilbara's inconsistent rainfall, the survey's lack of quadrat-based rainfall data and the flora and fauna's reliance on rainfall events to 'boom', followed swiftly by a bust, has meant that any comparison between quadrats has to be viewed with caution.

\section{Vicariance}

The apparent distributional limitations of a number of species and the high degree of allopatry 
between several pairs of closely related species help to highlight the broad subregional patterns that appeared in the survey area analysis. These distributional patterns consistently indicate a regional division into a southern and a northern Pilbara, divided by the Fortescue River and plain. This division is also seen in Mulga (Acacia aneura) where the Fortescue Plain is regarded as the northern limit of this species.

\section{ACKNOWLEDGEMENTS}

Major funding for this project was provided by the WA Department of Environment and Conservation, with contributions from the Western Australian Museum, the Commonwealth Government (through the Natural Heritage Trust; NHT2) and Straits Resources. Substantial, in-kind support was also provided by Rio Tinto Iron Ore, BHP Billiton Iron Ore and Kitchener Mining (Bamboo Creek Operation). We gratefully acknowledge the numerous Pilbara pastoralists and Aboriginal communities for permission to access their leases and/or land. In particular, Robyn and Tony Richardson of Mt Florance Station provided free access to their camping ground for the survey quadrat installation and sampling teams, and Rio Tinto Iron Ore provided access to subsidised housing for the first installation team while operating out of Karratha. DEC Pilbara Region and National Park staff at Karratha and at Karijini and Millstream-Chichester National Parks provided subsidised accommodation for pit-trap installation teams and sampling teams; Department of Water provided access to Tabletop Hill, Harding Dam and quadrats along the West Pilbara water supply pipeline. Rio Tinto Iron Ore and BHP Billiton Iron Ore are acknowledged for permission to enter their exploration leases and for granting access to their rail access roads. We also thank N.A. Guthrie, G. Owen, J. Dunlop, E. Ladhams, S. Danti and J. Angus for help sorting and identifying specimens and data collation. B.Y. Main for her valuable taxonomic and ecological contribution to the trapdoor spider section. N.L. McKenzie, A.H. Burbidge and M. Williams provided analytical advice. N.L. McKenzie and S. van Leeuwen selected the quadrats, J.K. Rolfe, R. Bromilow, P. Cullen, T. Farmer, D. Kamien, B. Muir, C. Parker, R. Whitelaw, J. Dunlop, A. Lang, W. Manson, J. Nolthenius and T. Smith installed the traps, and logistical support was provided by S. van Leeuwen, R. Bromilow, M. Hughes and T. Smith.

\section{REFERENCES}

Baehr, B. (2003a). Revision of the Australian spider genus Habronestes (Araneae: Zodariidae): species of New South Wales and the Australian Capital Territory. Records of the Australian Museum 55: 343-376.
Baehr, B. (2003b). Three new endemic genera from the Asteron-complex (Araneae: Zodariidae) from Australia: Basasteron, Euasteron and Spinasteron. Memoirs of the Queensland Museum 49: 1-27.

Baehr, B. (2004). The systematics of a new endemic Australian genus of ant spiders Masasteron (Araneae: Zodariidae). Invertebrate Systematics 18: 661-691.

Baehr, B. (2005). The generic relationships of the new endemic Australian ant spider genus Notasteron (Araneae: Zodariidae). The Journal of Arachnology 33: 445-455.

Baehr, B. and Churchill, T.B. (2003). Revision of the endemic Australian genus Spinasteron (Araneae: Zodariidae): taxonomy, phylogeny and biogeography. Invertebrate Systematics 17: 641-665.

Baehr, B.C., Harvey, M.S. and Smith, H.M. (2010). A review of the new endemic Australian goblin spider genus Cavisternum (Araneae: Oonopidae). American Museum Novitates 3684: 1-40.

Baehr, B. and Jocqué, R. (2000). Revisions of genera in the Asteron-complex (Araneae: Zodariidae): the new genera Cavasteron and Minasteron. Records of the Western Australian Museum 20: 1-30.

Baehr, B. and Jocqué, R. (2001). Revisions of genera in the Asteron-complex (Araneae: Zodariidae): new genera Pentasteron, Phenasteron, Leptasteron and Subasteron. Memoirs of the Queensland Museum 46: 359-385.

Beard, J.S. (1990). Plant life of Western Australia. Kangaroo Press: Kenthurst, Australia.

Belbin, L. (1995). PATN technical reference. CSIRO Division of Wildlife and Ecology: Canberra, Australia.

Brennan, K.E.C., Majer, J.D. and Reygart, N. (1999). Determination of an optimal pitfall trap size for sampling spiders in a Western Australian Jarrah forest. Journal of Insect Conservation 3: 297-307.

Churchill, T. and Arthur, J. (1999). Measuring spider richness: effects of different sampling methods and spatial and temporal scales. Journal of Insect Conservation 3: 281-295.

Clarke, K.R. and Gorley, R.N. (2006). PRIMER v6: user manual/tutorial. PRIMER-E Ltd: Plymouth, UK.

Colwell, R.K. (2006). EstimateS. Statistical estimation of species richness and shared species from samples Version 8.0. http:/ / viceroy.eeb.uconn.edu/estimates

Curtis, D.J. (1980). Pitfalls in spider community studies (Arachnida - Araneae). Journal of Arachnology 8: 271-280.

Davies, V.T. and Żabka, M. (1989). Illustrated keys to the genera of jumping spiders (Araneae: Salticidae) in Australia. Memoirs of the Queensland Museum 27: 189-266.

Durrant, B.J. (2004). Biogeographical patterns of zodariid spiders (Araneae: Zodariidae) in the wheatbelt region, Western Australia. Records of the Western Australian Museum, Supplement 67: 217-230.

Faulder, R.J. (1985). Some species of Aganippe (Araneae: Ctenizidae) from eastern Australia. Proceedings of the Linnean Society of New South Wales 108: 83-96.

Faulder, R.J. (1995a). Systematics and Biogeography of the Spider Genus Missulena Walckenaer. Master of Science, Department of Crop Sciences, Faculty of Agriculture, The University of Sydney: Sydney, Australia. 
Faulder, R.J. (1995b). Two new species of the Australian spider genus Missulena Walckenaer (Aranenae: Actinopodidae). Records of the Western Australian Museum, Supplement 52: 73-78.

Framenau, V.W. (2005). The wolf spider genus Artoria Thorell in Australia: new synonymies and generic transfers (Araneae, Lycosidae). Records of the Western Australian Museum 22: 265-292.

Framenau, V.W. (2006a). Knoelle, a new monotypic wolf spider genus from Australia (Araneae: Lycosidae). Zootaxa 1281: 55-67.

Framenau, V.W. (2006b). Revision of the Australian wolf spider genus Anomalosa Roewer, 1960 (Araneae: Lycosidae). Zootaxa 1304: 1-20.

Framenau, V.W. (2006c). The wolf spider genus Venatrix Roewer: new species, synonymies and generic transfers (Araneae, Lycosidae). Records of the Western Austalian Museum 23: 145-166.

Framenau, V.W. (2007). Revision of the new Australian genus Artoriopsis in a new subfamily of wolf spiders, Artoriinae (Araneae: Lycosidae). Zootaxa 1391: 1-34.

Framenau, V.W. (2008). A new wolf spider species of the genus Artoria from Western Australia (Araneae: Lycosidae). Records of the Western Austalian Museum 24: 363-368.

Framenau, V.W. and Baehr, B.C. (2007). Revision of the Australian wolf spider genus Dingosa Roewer, 1955 (Araneae, Lycosidae, Lycosinae). Journal of Natural History 41: 1603-1629.

Framenau, V.W., Gotch, T.B. and Austin, A.D. (2006). The wolf spiders of artesian springs in arid South Australia, with a revalidation of Tetralycosa (Araneae, Lycosidae). Journal of Arachnology 34: 1-36.

Framenau, V.W. and Vink, C.J. (2001). Revision of the wolf spider genus Venatrix Roewer (Araneae: Lycosidae). Invertebrate Taxonomy 15: 927-970.

Framenau, V.W. and Yoo, J.-S. (2006). Systematics of the new Australian wolf spider genus Tuberculosa (Araneae, Lycosidae). Invertebrate Systematics 20: 185-202.

Gaston, K.J. (2000). Global patterns in biodiversity. Nature 405: 220-227.

Guthrie, N.A. and Waldock, J.M. (2004). Patterns in the composition of the jumping spider (Arachnida: Araneae: Salticidae) assemblage from the wheatbelt region, Western Australia. Records of the Western Australian Museum, Supplement 67: 203-216.

Harvey, M.S. (2002). Short-range endemism among the Australian fauna: some examples from non-marine environments. Invertebrate Systematics 16: 555-570.

Harvey, M.S., Sampey, A., West, P.L.J. and Waldock, J.M. (2000). Araneomorph spiders from the southern Carnarvon Basin, Western Australia: a consideration of regional biogeographic relationships. Records of the Western Australian Museum, Supplement 61: 295-321.

Harvey, M.S., Waldock, J.M., Guthrie, N.A., Durrant, B.J. and McKenzie, N.L. (2004). Patterns in the composition in ground-dwelling araneomorph spider communities in the Western Australian wheatbelt. Records of the Western Australian Museum, Supplement 67: 257-291.

Hawkins, B.A. and Diniz-Filho, J.A.F. (2004). 'Latitude' and geographic patterns. Ecography 27: 268-272.
Hedin, M. and Bond, J.E. (2006). Molecular phylogenetics of the spider infraorder Mygalomorphae using nuclear rRNA genes (18S and 28S): conflict and agreement with current systems of classification. Molecular Phylogenetics and Evolution 41: 454-471.

Hillebrand, H. (2004). On the generality of the latitudinal diversity gradient. American Naturalist 163: 192-211.

Huber, B. A. (2001). The pholcids of Australia (Araneae: Pholcidae): taxonomy, biogeography, and relationships. Bulletin of the American Museum of Natural History 260: 1-144.

Jocqué, R. (1995). Notes on Australian Zodariidae (Araneae), I, New taxa and key to the genera. Records of the Australian Museum 47: 117-140.

Kendrick, P. (2003a). Pilbara 2 (PIL2-Fortescue subregion) (pp 559-567). In: May, J.E. and McKenzie, N.L. (eds), A biodiversity audit of Western Australia's biogeographical subregions in 2002. Western Australian Department of Conservation and Land Management: [Perth], Australia.

Kendrick, P. (2003b). Pilbara 3 (PIL3-Hamersley subregion) (pp 568-580). In: May, J.E. and McKenzie, N.L. (eds), A biodiversity audit of Western Australia's biogeographical subregions in 2002. Western Australian Department of Conservation and Land Management: [Perth], Australia.

Kendrick, P. and McKenzie, N.M. (2003). Pilbara 1 (PIL1Chichester subregion) (pp 547-558). In: May, J.E. and McKenzie, N.L. (eds), A biodiversity audit of Western Australia's biogeographical subregions in 2002. Western Australian Department of Conservation and Land Management: [Perth], Australia.

Kendrick, P. and Stanley, F. (2003). Pilbara 4 (PIL4Roebourne subregion) (pp 581-593). In: May, J.E. and McKenzie, N.L. (eds), A biodiversity audit of Western Australia's biogeographical subregions in 2002. Western Australian Department of Conservation and Land Management: [Perth], Australia.

Langlands, P. and Framenau, V.W. (2010). Systematic revision of Hoggicosa Roewer, 1960, the Australian 'bicolor' group of wolf spiders (Araneae: Lycosidae). Zoological Journal of the Linnean Society 158: 83-123.

Main, B.Y. (1956). Observations on the burrow and natural history of the trapdoor spider Missulena (Ctenizidae). The Western Australian Naturalist 5: 73-80.

Main, B.Y. (1957). Occurrence of the trap-door spider Conothele malayana (Doleschall) in Australia (Mygalomorphae: Ctenizidae). The Western Australian Naturalist 5: 209-216.

Main, B.Y. (1976). Spiders. Collins: Sydney, Australia, London, U.K.

Main, B.Y. (1977). Spiders (pp 100-107). In: Kenneally, K.F. (ed.), The natural history of the Wongan Hills. Handbook No. 11. Western Australian Naturalists' Club: Perth, Australia.

Main, B.Y. (1982). Further studies on the systematics of Australian Diplurinae (Araneae: Mygalomorphae, Dipluridae): the taxonomic status of Proshermacha Simon and Chenistonia tepperi Hogg. Australian Entomological Magazine 8: 83-88.

Main, B.Y. (1983). Further studies on the systematics of 
Australian Diplurinae (Chelicerata: Mygalomorphae: Dipluridae): two new genera from southwestern Australia. Journal of Natural History 17: 923-949.

Main, B.Y. (1985). Further studies on the systematics of ctenizid trapdoor spiders: a review of the Australian genera (Araneae: Mygalomorphae: Ctenizidae). Australian Journal of Zoology, Supplementary Series 108: 1-84.

Main, B.Y. (1986). Trapdoors of Australian mygalomorph spiders: protection or predation? Actas X Congreso Internacional de Aracnologia 1: 95-102.

Main, B.Y. (1991). Kimberley spiders: rainforest strongholds (pp 271-293). In: McKenzie, N.L., Johnston, R.B. and Kendrick, P.G. (eds), Kimberley rainforests of Australia, Surrey Beatty: Chipping Norton, Australia.

Main, B.Y. (2000). Biosystematics of two new species of unusually coloured Australian mygalomorph spiders, Arbanitis (Araneae: Idiopidae), from south-western Australia. Journal of the Royal Society of Western Australia 83: 93-97.

Main, B.Y. (2008). A new species of the mygalomorph spider genus Yilgarnia from the Western Australian wheatbelt (Araneae: Nemesiidae). Records of the Western Australian Museum 24: 321-324.

Main, B.Y., Sampey, A. and West, P.L.J. (2000). Mygalomorph spiders of the southern Carnarvon Basin, Western Australia, Records of the Australian Museum Supplement 61: 281-293.

McKay, R.J. (1979). The wolf spiders of Australia (Araneae: Lycosidae), 10, a new species of the genus Flanona Simon. Memoirs of the Queensland Museum 19: 231-235.

McKenzie, N.L., van Leeuwen, S. and Pinder, A.M. (2009). Introduction to the Pilbara biodiversity survey, 2002-2007. Records of the Western Australian Museum, Supplement 78: 3-89.

Murphy, N.P., Framenau, V.W., Donnellan, S.C., Harvey, M.S., Park, Y.-C. and Austin, A.D. (2006). Phylogenetic reconstruction of the wolf spiders (Araneae: Lycosidae) using sequences from the $12 \mathrm{~S}$ rRNA, 28S rRNA, and NADH1 genes: implications for classification, biogeography, and the evolution of web building behaviour. Molecular Phylogenetics and Evolution 38: 583-602.

Ott, R. and Harvey, M.S. (2008a). A new species of Pelicinus from Barrow Island, Western Australia (Araneae: Oonopidae). Arthropoda Selecta 17: 81-85.

Ott, R. and Harvey, M. S. (2008b). A new species of Xestaspis (Araneae: Oonopidae) from the arid zone of Western Australia. Records of the Western Australian Museum 25: 337-342.

Platnick, N.I. (2000). A relimitation and revision of the Australasian ground spider family Lamponidae (Araneae: Gnaphosoidea). Bulletin of the American Museum of Natural History 254: 1-330.

Platnick, N.I. (2002). A revision of the Australasian ground spiders of the families Ammoxenidae, Cithaeronidae, Gallieniellidae and Trochanteriidae (Araneae: Gnaphosoidea). Bulletin of the American Museum of Natural History 271: 1-243.

Platnick, N.I. (2004). On a third group of flattened ground spiders from Australia (Araneae, Lamponidae). American Museum Novitates 3462: 1-7.

Platnick, N.I. (2010). The world spider catalog, Version 10.5. American Museum of Natural History: New York. http:/ / research.amnh.org/entomology/spiders / catalog/index.html

Platnick, N.I. and Baehr, B. (2006). A revision of the Australasian ground spiders of the family Prodidomidae (Araneae: Gnaphosoidea). Bulletin of the American Museum of Natural History 298: 1-287.

Raven, R.J. (1981). A review of the Australian genera of the mygalomorph spider subfamily Diplurinae (Dipluridae: Chelicerata). Australian Journal of Zoology 29: 321-363.

Raven, R.J. (1984). A revision of the Aname maculata species group (Dipluridae, Araneae) with notes on biogeography. Journal of Arachnology 12: 177-193.

Raven, R.J. (1985). A revision of the Aname pallida speciesgroup in northern Australia (Anaminae: Nemesiidae: Araneae). Australian Journal of Zoology 33: 377-409.

Raven, R.J. (1994). Mygalomorph spiders of the Barychelidae in Australia and the western Pacific. Memoirs of the Queensland Museum 35: 291-706.

Raven, R.J. (2000). Taxonomica Araneae, I, Barychelidae, Theraphosidae, Nemesiidae and Dipluridae (Araneae). Memoirs of the Queensland Museum 45: 569-575.

Raven, R.J., Baehr, B.C. and Harvey, M.S. (2002). Spiders of Australia: interactive identification to subfamily. CSIRO Publishing: Melbourne, and Australian Biological Resources Study: Canberra, Australia.

Raven, R.J. and Wishart, G. (2005). The trapdoor spider Arbanitis L. Koch (Idiopidae: Mygalomorphae) in Australia. Memoirs of the Queensland Museum 51: 531-557.

Sneath, P.H.A. and Sokal, R.R. (1973). Numerical taxonomy: the principles and practice of numerical classification. Freeman: San Francisco, USA.

Standen, V. (2000). The adequacy of collecting techniques for estimating species richness of grassland invertebrates. Journal of Applied Ecology 37: 884-893.

Thackway, R. and Cresswell, I.D. (1995). An Interim Biogeographic Regionalisation for Australia: a framework for establishing the national system of reserves, Version 4.0. Australian Nature Conservation Agency: Canberra, Australia.

Topping, C.J. and Sunderland, K.D. (1992). Limitations to the use of pitfall traps in ecological studies exemplified by a study of spiders in a field of winter wheat. Journal of Applied Ecology 29: 485-491.

Uetz, G.W. and Unzicker, J. (1976). Pitfall trapping ecological studies of wandering spiders. Journal of Arachnology 3: 101-111.

Waldock, J.M. (2002). Redescription of Lycidas chrysomelas (Simon) (Araneae: Salticidae). Records of the Western Australian Museum 21: 227-234.

Waldock, J.M. (2009). A new species of jumping spider of the genus Paraplatoides (Araneae: Salticidae) from Western Australia. Records of the Western Australian Museum 25: 305-308.

Yoo, J.-S. and Framenau, V.W. (2006). Systematics and biogeography of the sheet-web building wolf spider 
genus Venonia (Araneae: Lycosidae). Invertebrate Systematics 20: 675-712.

Żabka, M. (1992). Salticidae (Arachnida: Araneae) of Oriental, Australian and Pacific regions, VII, Paraplatoides and Grayenulla - new genera from Australia and New Caledonia. Records of the Australian Museum 44: 165-183.

Żabka, M. (1992). Salticidae (Arachnida: Araneae) of Oriental, Australian and Pacific regions, VIII, a new genus from Australia. Records of the Western Australian Museum 15: 673-684.

Żabka, M. (1994). Salticidae (Arachnida: Araneae) of
Oriental, Australian and Pacific regions, X, Genus Simaetha Thorell. Records of the Western Australian Museum 16: 499-534.

Żabka, M. (2006). Salticidae (Arachnida: Araneae) from Oriental, Australian and Pacific Regions, XIX, genus Pellenes Simon, 1876 in Australia. Annales Zoologici (Warsaw) 56: 567-573.

Żabka, M. and Gray, M.R. (2002). Salticidae (Arachnida: Araneae) from Oriental, Australian and Pacific Regions, XVI, new species of Grayenulla and Afraflacilla. Records of the Australian Museum 54: 269-274.

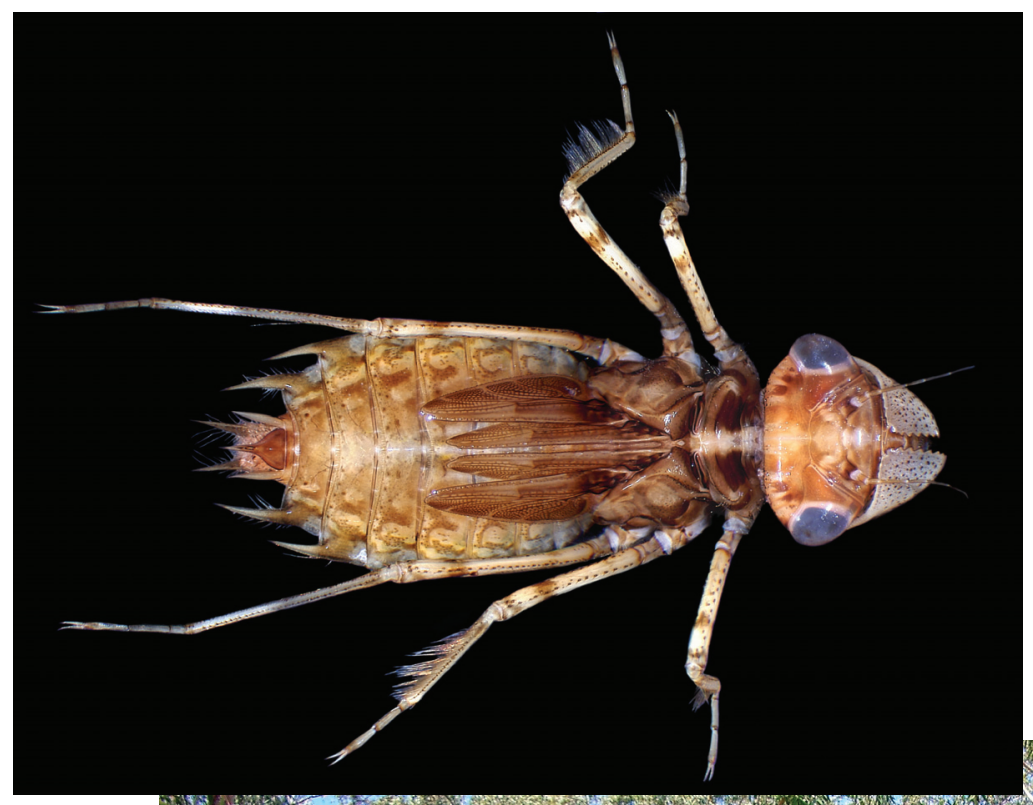

TOP: Nymph of Trapezostigmata stenoloba, a common dragonfly of Pilbara wetlands (J.M. McRae).

BOTTOM: Weeli Wolli, a permanent creek fed by discharging hyporheic water (N.L. McKenzie).

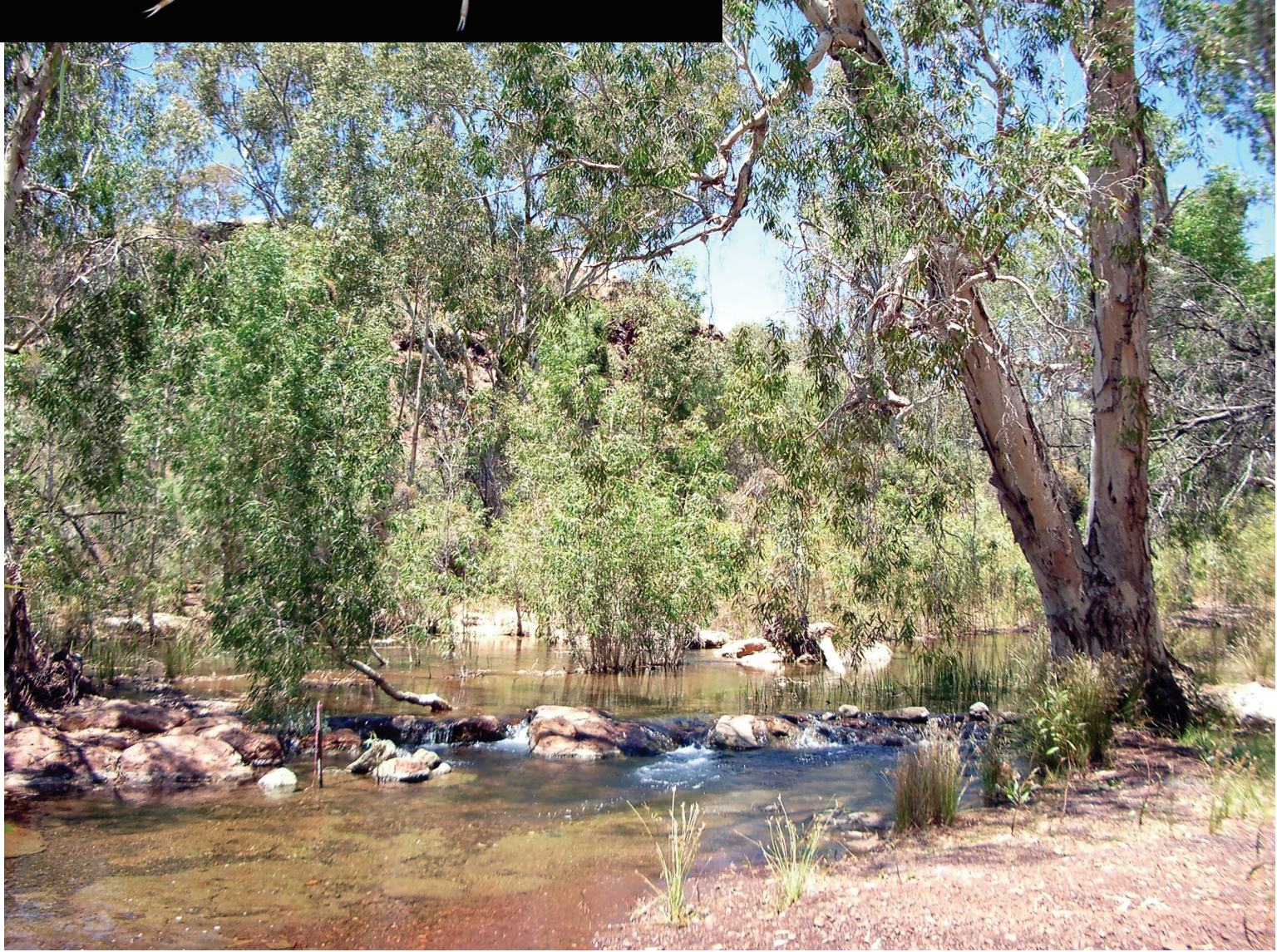

